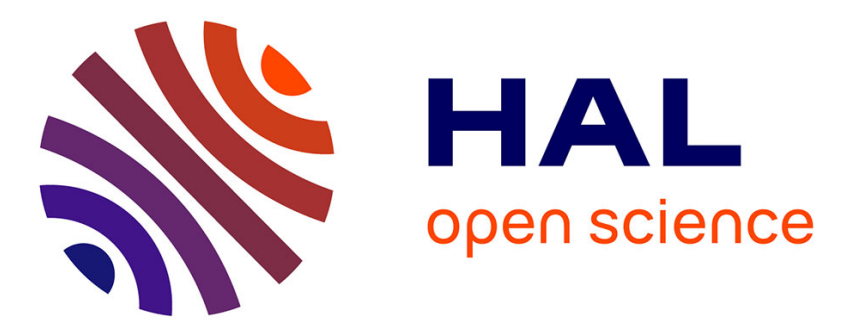

\title{
Functional assessment of variants in the TSC1 and TSC2 genes identified in individuals with Tuberous Sclerosis Complex
}

Mark Nellist, Marianne Hoogeveen-Westerveld, Marjolein Wentink, Diana van den Heuvel, Melika Mozaffari, Rosemary Ekong, Sue Povey, Johan T. den Dunnen, Kay Metcalfe, Stephanie Vallee, et al.

\section{To cite this version:}

Mark Nellist, Marianne Hoogeveen-Westerveld, Marjolein Wentink, Diana van den Heuvel, Melika Mozaffari, et al.. Functional assessment of variants in the TSC1 and TSC2 genes identified in individuals with Tuberous Sclerosis Complex. Human Mutation, 2011, 32 (4), pp.424. 10.1002/humu.21451. hal-00620580

\section{HAL Id: hal-00620580 https://hal.science/hal-00620580}

Submitted on 8 Sep 2011

HAL is a multi-disciplinary open access archive for the deposit and dissemination of scientific research documents, whether they are published or not. The documents may come from teaching and research institutions in France or abroad, or from public or private research centers.
L'archive ouverte pluridisciplinaire HAL, est destinée au dépôt et à la diffusion de documents scientifiques de niveau recherche, publiés ou non, émanant des établissements d'enseignement et de recherche français ou étrangers, des laboratoires publics ou privés. 


\section{Human Mutation}

WILEY

\section{Functional assessment of variants in the TSC1 and TSC2 genes identified in individuals with Tuberous Sclerosis Complex}

\begin{tabular}{|c|c|}
\hline Journal: & Human Mutation \\
\hline Manuscript ID: & humu-2010-0472.R1 \\
\hline Wiley - Manuscript type: & Research Article \\
\hline $\begin{array}{r}\text { Date Submitted by the } \\
\text { Author: }\end{array}$ & 01-Dec-2010 \\
\hline Complete List of Authors: & $\begin{array}{l}\text { Nellist, Mark; Erasmus Medical Center, Clinical Genetics } \\
\text { Hoogeveen-Westerveld, Marianne; Erasmus MC } \\
\text { Wentink, Marjolein; Erasmus MC } \\
\text { van den Heuvel, Diana; Erasmus MC } \\
\text { Mozaffari, Melika; Erasmus MC } \\
\text { Ekong, Rosemary; University College } \\
\text { Povey, Sue; University College } \\
\text { den Dunnen, Johan; Leiden University Medical Center, Human \& } \\
\text { Clinical Genetics } \\
\text { Metcalfe, Kay; Central Manchester University Hospitals NHS } \\
\text { Foundation Trust } \\
\text { Vallee, Stephanie; Dartmouth-Hitchcock Medical Center } \\
\text { Krüger, Stefan; Gemeinschaftspraxis für Humangenetik, Center for } \\
\text { Human Genetics } \\
\text { Shashi, Vandana; Duke University } \\
\text { Bergoffen, JoAnn; Kaiser Permanente San Jose Medical Center } \\
\text { Elmslie, Frances; St. George's Hospital } \\
\text { Kwiatkowski, David; Brigham and Women's Hospital, Medicine } \\
\text { Sampson, Julian; Cardiff University, Medical Genetics } \\
\text { Vidales, Concha; Policlinica Gipuzka } \\
\text { Dzarir, Jacinta; The Prince of Wales Hospital } \\
\text { Garcia-Planells, Javier; University of Valencia } \\
\text { Dies, Kira; Children's Hospital } \\
\text { Maat-Kievit, Anneke; Erasmus Medical Center, Department of } \\
\text { Clinical Genetics } \\
\text { van den Ouweland, Ans M.W.; ErasmusMC, Clinical Genetics } \\
\text { Halley, Dicky; Erasmus MC }\end{array}$ \\
\hline Key Words: & tuberous sclerosis complex, TSC1, TSC2, unclassified variants \\
\hline
\end{tabular}




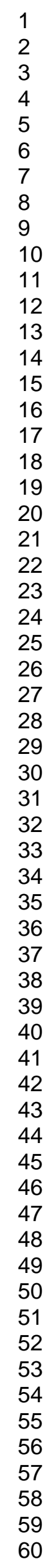

\section{SCHOLARONE ${ }^{m}$ Manuscripts}

7

25

26

27

29

30

32

33

34

35

36

37

39

40

41

42

44

45

46

47

48

50

51

52

54

55

57

58

59

60

John Wiley \& Sons, Inc. 


\title{
Title page:[Human Mutation submission]
}

\section{Functional assessment of variants in the TSC1 and TSC2 genes identified in individuals with Tuberous Sclerosis Complex}

\author{
Marianne Hoogeveen-Westerveld ${ }^{1}$, Marjolein Wentink ${ }^{1}$, Diana van den Heuvel $^{1}$, Melika \\ Mozaffari $^{1}$, Rosemary Ekong ${ }^{2}$, Sue Povey ${ }^{2}$, Johan T. den Dunnen ${ }^{3}$, Kay Metcalfe ${ }^{4}$, \\ Stephanie Vallee ${ }^{5}$, Stefan Krueger ${ }^{6}$, JoAnn Bergoffen ${ }^{7}$, Vandana Shashi ${ }^{8}$, Frances \\ Elmslie $^{9}$, David Kwiatkowski ${ }^{10}$, Julian Sampson ${ }^{11}$, Concha Vidales ${ }^{12}$, Jacinta Dzarir ${ }^{13}$, \\ Javier Garcia-Planells ${ }^{14}$, Kira Dies ${ }^{15}$, Anneke Maat-Kievit ${ }^{1}$, Ans van den Ouweland ${ }^{1}$, \\ Dicky Halley $^{1}$ and Mark Nellist ${ }^{1}$
}

${ }^{1}$ Department of Clinical Genetics, Erasmus Medical Centre, 3015 GE Rotterdam, The Netherlands.

${ }^{2}$ Research Department of Genetics, Evolution and Environment, University College London, London NW1 2HE, U.K.

${ }^{3}$ Department of Human and Clinical Genetics, Leiden University Medical Centre, 2333

ZC Leiden, The Netherlands.

${ }^{4}$ Department of Genetic Medicine, Central Manchester University Hospitals NHS

Foundation Trust, Manchester M13 9WL, U.K.

${ }^{5}$ Department of Clinical Genetics, Dartmouth-Hitchcock Medical Center, Lebanon, NH 03756, U.S.A.

${ }^{6}$ Center for Human Genetics, Gutenbergstr. 5, D-01307 Dresden, Germany.

${ }^{7}$ Department of Genetics, Kaiser Permanente San Jose Medical Center, 5755 Cottle Road, San Jose, CA 95123, U.S.A. 
1

2

3

4

5

6

7

8

9

10

11

12

13

14

15

16

17

18

19

20

21

22

23

24

25

26

27

28

29

30

31

32

33

34

35

36

37

38

39

40

41

42

43

44

45

46

47

48

49

50

51

52

53

54

55

56

57

58

59

60

${ }^{8}$ Department of Pediatrics, Duke University Medical Center, Durham, NC, U.S.A.

${ }^{9}$ Department of Medical Genetics, St. George's Hospital, London SW17 ORE, U.K.

${ }^{10}$ Translational Medicine Division, Brigham and Womens Hospital, Boston MA 02115,

U.S.A.

${ }^{11}$ Institute of Medical Genetics, Cardiff University , Heath Park, Cardiff CF4 4XN, U.K.

Deleted: of Wales College of Medicine

${ }^{12}$ Department of Molecular Genetics, Policlinica Gipuzka, 20009 San Sebastian, Spain.

${ }^{13}$ Department of Molecular Genetics, The Prince of Wales Hospital, Randwick,

Australia.

${ }^{14}$ Institute of Medical Genomics, University of Valencia, Valencia, Spain.

${ }^{15}$ Department of Neurology, Children's Hospital Boston, Boston MA 02115, U.S.A.

To whom correspondence should be addressed: Dr. Mark Nellist, Department of

Clinical Genetics, Erasmus Medical Centre, Dr. Molewaterplein 50, 3015 GE

Rotterdam, The Netherlands, Tel: +31 10 7044628; Fax: +31 10 7044736; email:

m.nellist@erasmusmc.nl

Running title: Functional assessment of TSC1 and TSC2 variants 


\begin{abstract}
The effects of missense changes and small in-frame deletions and insertions on protein function are not easy to predict and the identification of such variants in individuals at risk of a genetic disease can complicate genetic counselling. One option is to perform functional tests to assess whether the variants affect protein function. We have used this strategy to characterise variants identified in the TSC1 and TSC2 genes in individuals with, or suspected of having, Tuberous Sclerosis Complex (TSC). Here we present an overview of our functional studies on 45 TSC1 and 107 TSC2 variants. Using a standardised protocol we classified 16 TSC1 variants and 70 TSC2 variants as pathogenic. In addition we identified 8 putative splice site mutations (5 TSC1 and 3 TSC2). The remaining 24 TSC1 and 34 TSC2 variants were classified as probably neutral.
\end{abstract}

Keywords: tuberous sclerosis complex, TSC1, TSC2, unclassified variants 


\section{Introduction}

Tuberous Sclerosis Complex (TSC) is an autosomal dominant disorder characterised by the development of hamartomas in a variety of organs and tissues, most notably the brain, skin and kidneys [Gomez et al., 1999]. Most individuals with TSC have epilepsy and many suffer from cognitive impairments and/or autismspectrum disorders. Mutations in either the TSC1 gene on chromosome 9q34 (OMIM \#605284) [van Slegtenhorst et al., 1997], or the TSC2 gene on chromosome 16p13.3 (OMIM \#191092) [European Chromosome 16 Tuberous Sclerosis Consortium, 1993] cause TSC and comprehensive mutation screens in TSC patients have identified a wide variety of pathogenic mutations [Jones et al., 1999; Niida et al., 1999; Dabora et al., 2001; Sancak et al., 2005; Au et al., 2007]. Most TSC1 and TSC2 mutations result in premature termination of the respective open-reading frame and complete inactivation of the mutated allele. However, approximately $25 \%$ of the mutations identified in the TSC2 gene and $1 \%$ of the mutations identified in TSCl, are non-terminating missense changes or small in-frame deletions or insertions [Sancak et al., 2005]. The consequences of such non-terminating changes are not easy to predict with certainty, making it difficult to distinguish disease-causing mutations from neutral (nonpathogenic) variants. In a cohort of 490 putative TSC cases, we identified 29 variants (6\% of the total) that could not be classified as either pathogenic or neutral from the available clinical and genetic data [Sancak et al., 2005]. In such cases, in vitro functional comparisons between the wild-type and variant proteins can help determine whether an unclassified variant (UV) is pathogenic or not [Nellist et al., 2008].

The TSC1 and TSC2 gene products, TSC1 and TSC2, interact to form a protein complex that integrates multiple growth factor- and energy-dependent signals to help

Deleted: $T S C 2$ mutations are generally associated with a more severe TSC phenotype [Dabora et al., 2001]. However, there are several reports of families where specific TSC2 missense mutations cosegregate with apparently mild forms of the disease [Khare et al., 2001; O'Connor et al., 2003; Mayer et al., 2004; Jansen et al., 2006], consistent with the proposal that specific types of $T S C 1$

or TSC2 mutation may help determine the clinical course of the disease [de Vries and Howe, 2007]. It would be useful to be able to identify TSC 1 and TSC2 variants that have reduced activity, as opposed to being completely inactive, and that might be less likely to lead to a severe TSC phenotype.II 
control cell growth [Inoki and Guan, 2009]. The N-terminal region of TSC2 is required for binding TSC1 [Li et al., 2004], while the TSC2 C-terminal region contains the active site of the complex, an "asparagine-thumb" GTPase activating protein (GAP) domain [Daumke et al., 2004]. The TSC1-TSC2 complex stimulates the GTPase activity of RHEB to promote the conversion of active, GTP-bound RHEB to inactive RHEB-GDP and thereby prevent the RHEB-GTP-dependent stimulation of the mammalian target of rapamycin (mTOR) complex 1 (TORC1) [Li et al., 2003]. In cells lacking either TSC1 or TSC2, the downstream targets of TORC1, including elongation factor 4E binding protein 1 (4E-BP1), p70 S6 kinase (S6K) and ribosomal protein S6, are constitutively phosphorylated [Zhang et al., 2003; Kwiatkowski et al., 2001].

The effects of specific amino acid changes on TSC1-TSC2 complex formation, on the activation of RHEB GTPase activity by the complex, and on the phosphorylation status of 4E-BP1, S6K and S6, have been investigated [Nellist et al., 2001; Inoki et al. 2002, Tee et al, 2002]. Previously, we used immunoblotting, double-label immunofluorescent microscopy, in-cell Western analysis and GAP assays to study the effects of 47 TSC2 missense and in-frame insertions/deletions and 26 TSC1 missense and in-frame insertions/deletions on TSC1-TSC2 activity [Nellist et al., 2005; Jansen et al., 2006, Jansen et al., 2008, Nellist et al., 2008, Nellist et al., 2009; Coevoets et al., 2009; Mozaffari et al., 2009]. Pathogenic missense changes in the N-terminal region of TSC1 (amino acids 50 - 224) reduced TSC1 stability [Nellist et al., 2009; Mozaffari et al., 2009], while pathogenic TSC2 missense changes had distinct effects on the TSC1TSC 2 complex, depending on the region of TSC2 that was affected. Some TSC 2 amino acid substitutions prevented TSC1-TSC2 complex formation while others did not affect TSC1-TSC2 binding, but still inactivated the complex [Nellist et al., 2005]. Here we compare 73 previously tested variants to 79 new variants (19 TSC1 and 60 TSC2) using 
1

3

4

5

6

7

8

9

10

11

12

13

14

15

16

17

18

19

20

21

22

23

24

25

26

a standardised protocol. To assess the effects of the variants on both the formation and activity of the TSC1-TSC2 complex we decided to use immunoblotting followed by infra-red scanner-based detection. In our experience, double-label microscopy and GAP assays were too labour-intensive and/or unreliable for routine use and, although the incell Western was a simple and reliable assay [Coevoets et al., 2009], it required large amounts of (expensive) antibodies and did not provide information on the TSC1-TSC2 interaction.

Our aim was to investigate the reliability of the assay, the degree of concordance between the in vitro results and computer-based predictive methods and, ultimately, to use the results of the functional assessment to determine whether variants identified in individuals with, or suspected of having, TSC were pathogenic. To assess the reliability of our functional studies we compared our results to the classifications of the variants listed in the TSC1 and TSC2 Leiden Open Variation Databases (LOVD) (http://www.lovd.nl/TSC1; http://www.lovd.n1/TSC2). Furthermore, we hoped to gain insight into the structural properties of TSC 1 and TSC 2 by comparing the properties of the different variants.

\section{Materials and Methods}

\section{TSC1 and TSC2 variants}

The relative positions of the variants selected for functional assessment are shown in Figure 1. All variants are listed in Supporting Tables S1, S2 and S3. The variants were compared to wild-type TSC1 (Genbank AF013168.1; GI: 2331280) and

\section{TSC2 (Genbank X75621; GI:450351), as originally described [van Slegtenhorst et al..,}

1997; European Chromosome 16 Tuberous Sclerosis Consortium, 1993] and it is 
therefore important to note that the TSC2 wild-type lacks the amino acids encoded by

the alternatively spliced exon 31 . The amino acid numbering according to the $\underline{T S C 2}$

Deleted: is isoform

LOVD (http://www.lovd.nl/TSC2), where this differs from the original numbering due

Deleted: $T S C 2$ database to the inclusion of exon 31 , is given in Supporting Table $\underline{S} 3$.

Nucleotide numbering reflects the cDNA numbering with +1 corresponding to

the A of the ATG translation initiation codon in the reference sequence, according to

journal guidelines (www.hgvs.org/mutnomen). The initiation codon is codon 1.

\section{Constructs and antisera}

Expression constructs encoding the TSC1 and TSC2 variants were derived from the wild-type expression constructs [Nellist et al., 2005] using the QuikChange sitedirected mutagenesis kit (Stratagene, La Jolla, U.S.A.). In each case the complete open reading frame of the mutated construct was verified by sequence analysis. DNA was prepared using the Plasmid Plus Midi Purification kit (Qiagen, Venlo, The

Netherlands). In most cases, multiple clones were isolated, verified and used for the assays described below. Other constructs used in this study have been described previously [Nellist et al., 2005]. Antibodies were purchased from Cell Signaling Technology (Danvers, U.S.A.) (1A5, anti T389 phospho-S6K mouse monoclonal; 9B11, anti-myc tag mouse monoclonal; anti-myc tag rabbit polyclonal), Li-Cor Biosciences (Lincoln, U.S.A.) (goat anti-rabbit $680 \mathrm{~nm}$ and goat anti-mouse $800 \mathrm{~nm}$ conjugates) or DAKO (Glostrup, Denmark) (cyanine (Cy2)-coupled secondary antibodies against mouse immunoglobulins), or have been described previously [van Slegtenhorst et al., 1998]. 
Transfection-based immunoblot assay for functional assessment of TSC1 and TSC2 variants

TSC1 and TSC2 variants were assayed using essentially the same protocol. HEK 293T cells were seeded into 24-well plates and grown overnight in Dulbecco's modified Eagle medium (DMEM) (Lonza, Verviers, Belgium) supplemented with $10 \%$ foetal bovine serum, $50 \mathrm{U} / \mathrm{ml}$ penicillin and $50 \mu \mathrm{g} / \mathrm{ml}$ streptomycin in a $10 \%$ carbon dioxide humidified incubator. Cells at $80-90 \%$ confluency were transfected with $0.2 \mu \mathrm{g}$ TSC2 expression construct, $0.4 \mu \mathrm{g}$ TSC1 expression construct and $0.1 \mu \mathrm{g}$ S6K expression construct using $2.1 \mu \mathrm{g}$ polyethyleneimine (Polysciences Inc., Warrington, U.S.A.) in DMEM, as described previously [Coevoets et al., 2009]. For control transfections, pcDNA3 vector DNA was added to make a total of $0.7 \mu \mathrm{g}$ DNA per transfection. Cells expressing the TSC2 variants were compared to cells expressing wild-type TSC1-TSC2, a known pathogenic variant (TSC2-R611Q [Nellist et al., 2005]), TSC1 and S6K only (no TSC2), and cells transfected with vector DNA only (control). Cells expressing the TSC1 variants were compared to wild-type TSC1-TSC2, a known pathogenic variant (TSC1-L117P [Nellist et al., 2009]), TSC2 and S6K only (no TSC1), TSC1 and S6K only (no TSC2) and cells transfected with vector DNA only (control).

After 4 hours the transfection mixtures were replaced with DMEM supplemented with $10 \%$ foetal bovine serum, $50 \mathrm{U} / \mathrm{ml}$ penicillin and $50 \mu \mathrm{g} / \mathrm{ml}$ streptomycin. Twenty-four hours after transfection the cells were transferred to ice, washed with phosphate-buffered saline (PBS) $\left(4^{\circ} \mathrm{C}\right)$ and harvested in $75 \mu$ lysis buffer (50 mM Tris- $\mathrm{HCl} \mathrm{pH} 8.0,150 \mathrm{mM} \mathrm{NaCl}, 50 \mathrm{mM} \mathrm{NaF}$ and $1 \%$ Triton X100, containing a protease inhibitor cocktail (Complete, Roche Molecular Biochemicals, Woerden, The Netherlands)). After centrifugation (10 $000 \mathrm{~g}$ for 10 minutes at $\left.4^{\circ} \mathrm{C}\right)$, the supernatant fractions were recovered, diluted in loading buffer and incubated at $96^{\circ} \mathrm{C}$ for 5 minutes 
prior to electrophoresis on Criterion ${ }^{\mathrm{TM}} 4-12 \%$ SDS-PAGE gradient gels (Bio-Rad, Hercules, U.S.A.). Proteins were transferred to nitrocellulose membranes according to the manufacturer's recommendations.

Blots were blocked for 1 hour at room temperature with 5\% low-fat milk powder (Campina Melkunie, Eindhoven, The Netherlands) in PBS and incubated overnight at $4{ }^{\circ} \mathrm{C}$ with the following primary antibodies: $1 / 15000$ dilution of 1895 (rabbit polyclonal against TSC2 [van Slegtenhorst et al., 1998]), 1/5 000 dilution of 2197 (rabbit polyclonal against TSC1 [van Slegtenhorst et al., 1998]), 1/5 000 dilution of a rabbit polyclonal against the myc epitope tag and 1/2 000 dilution of 1A5 (mouse monoclonal against p70 S6 kinase (S6K) phosphorylated at amino acid T389). Antibodies were diluted in PBS containing $0.1 \%$ Tween 20 (PBST) (Sigma-Aldrich Fine Chemicals, Poole, U.K). After washing 3 times for 5 minutes in PBST, the blots were incubated for 1 hour at room temperature in the dark in PBST containing 1/10 000 dilutions of goat anti-rabbit $680 \mathrm{~nm}$ and goat anti-mouse $800 \mathrm{~nm}$ secondary antibodies. After washing 3 times for 5 minutes in PBST and once in PBS, the blots were scanned using the Odyssey ${ }^{\mathrm{TM}}$ Infrared Imager (Li-Cor Biosciences) at default intensity, medium quality, $169 \mu \mathrm{m}$ resolution with $0 \mathrm{~mm}$ focus offset. To estimate the expression levels of the different proteins and the ratio of T389-phosphorylated S6K to total S6K, in the presence of the different TSC1 and TSC2 variants, the scans were analysed using the Odyssey quantification software. The integrated intensities of the protein bands were determined using default settings with the 3 pixel width border mean average background correction method. To correct for the detection of endogenous proteins, we subtracted the signals detected in control cells (transfected with vector DNA only) from the corresponding TSC2, TSC1, S6K and T389-phosphorylated S6K signals for all variants. 

previously [Mozaffari et al., 2009] using a Leica DM RXA microscope and Image ProPlus version 6 image analysis software.

\title{
Prediction analysis
}

To investigate whether the TSC1 and TSC2 nucleotide changes might affect RNA splicing, 3 different splice-site prediction programs were used: www.cbs.dtu.dk/services/NetGene2, www.genet.sickkids.on.ca/ ali/ splicesitefinder.html, and www.fruitfly.org/seq_tools/splice.html.

To investigate whether the TSC 1 and TSC 2 amino acid substitutions were likely to affect TSC1-TSC2 structure and function, the Sorting Intolerant From Tolerant (SIFT) algorithm was used [Ng and Henikoff, 2006]. SIFT scores were calculated using multiple sequence alignments of TSC1 and TSC2 from 16 different species (human, chimpanzee, maccaca, cow, dog, horse, mouse, rat (TSC1 only), chicken, zebrafish (TSC2 only), pufferfish, honey bee (TSC1 only), fruitfly, mosquito, methylotrophic yeast (TSC2 only) and fission yeast).

\author{
Results \\ Immunoblot analysis \\ We compared 152 variants (45 TSC1 and 107 TSC2), including 79 previously \\ untested variants (19 TSC1 and 60 TSC2). Each variant was tested in at least 4 \\ independent transfection experiments. In each experiment, the integrated intensities of
}


the bands on the immunoblot corresponding to TSC2, TSC1, total S6K and T389-

phosphorylated S6K were determined for each variant, relative to the integrated intensities of the bands for wild-type TSC1-TSC2. Examples of immunoblots of 13

TSC1 variants and 15 TSC2 variants are shown in Supporting Figures S1 and S2 respectively. The mean values for the TSC2, TSC1 and S6K signals and the mean T389/S6K ratios (see below) for all the variants tested are shown in Figures $\underset{2}{2}{ }_{3}$ and 4 . First, to determine whether the transfection efficiencies for the different variant

Deleted: 2

Deleted: 3

Deleted: 4

Deleted: 5

Deleted: 6

Deleted: 4

Deleted: 5D

Deleted: 6

$3 \mathrm{D}$ and $4 \mathrm{D}$, the $\mathrm{S} 6 \mathrm{~K}$ signals were relatively constant for all the variants and controls, indicating that the transfection efficiencies were comparable between the different variants. For most variants we tested multiple DNA preparations. We did not observe large differences between the replicate DNA preparations, indicating that the quality of the different transfected DNAs was uniform (Supporting Figure S3). Furthermore, altering the amount of DNA used for transfection resulted in relatively small changes in the signals detected on the blots, indicating that the assay was robust with respect to the amount of transfected DNA (Supporting Figure S4).

Next, the ratio of the T389-phosphorylated S6K signal to the total S6K signal was determined for each variant, relative to wild-type TSC1-TSC2. We referred to this as the T389/S6K ratio. The higher the T389/S6K ratio, the higher the estimated activity of TORC1, and therefore the lower the activity of the exogenously expressed TSC1 and TSC2. The mean T389/S6K ratios for the TSC1 and TSC2 variants are shown in Figures $2 \mathrm{C}, 3 \mathrm{C}$ and $4 \mathrm{C}$. To determine whether the T389/S6K ratios for the variants were significantly increased relative to wild-type TSC1-TSC2, we performed Student's t-

\begin{tabular}{|l|}
\hline Deleted: 4 \\
\hline Deleted: 5 \\
\hline Deleted: 6
\end{tabular}
tests. This was the primary criterium for deciding whether a variant was disease- 
causing. We classified the variants with a significantly higher T389/S6K ratio than wild-type TSC1-TSC2 as pathogenic (p value < 0.05). Sixteen TSC1 variants $(36 \%$; see

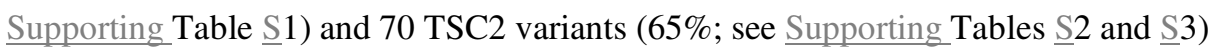
were classified as pathogenic. For variants where the T389/S6K ratio was not significantly higher than wild-type TSC1-TSC2 ( $\mathrm{p}>0.05)$, we compared the T389/S6K ratio to the pathogenic variant that was included in each transfection experiment (TSC2 R611Q for TSC2 variants; TSC1 L117P for TSC1 variants). All the variants that did not have a significantly higher T389/S6K ratio than wild-type TSC1-TSC2, had a significantly lower T389/S6K ratio than the corresponding pathogenic variant, and were therefore considered to be active in our assay. We classified these variants as probably neutral.

In addition to the T389/S6K ratio, we compared the signals of the TSC1 and TSC2 variants to the corresponding signals for the wild-type proteins (Figures 2B, 3A and 4A). Variant signals significantly less than that of the wild-type indicated that the steady state expression of the variant was reduced, either because the variant $\mathrm{mRNA}$ was less stable or translated less efficiently than the wild-type mRNA, or that the variant protein was unstable, Therefore, although we could not distinguish between effects on mRNA or protein stability, we classified variants with a significantly reduced

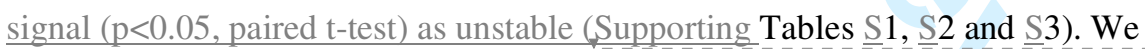
identified 16 unstable TSC1 variants and 38 unstable TSC2 variants. All of the unstable TSC1 variants had been classified as pathogenic, according to the comparisons between the variant and wild-type T389/S6K ratios. Furthermore, consistent with a previous study [Mozaffari et al., 2009], all the unstable TSC1 variants gave a diffuse cytoplasmic signal as detected by immunofluorescent microscopy, in contrast to wild-type TSC1 and the stable TSC1 variants that all gave a characteristic punctate localisation pattern (data
Deleted: In most cases it was fairly clear whether a variant inhibited S6K T389 phosphorylation or not. However, for a few variants we noticed that there was more inter-experiment variation. Some variants appeared more effective at inhibiting S6K T389 phosphorylation in one experiment compared to the next. An example of this variation is shown in

Supplemental Figure 1. Nevertheless, a

Deleted: ccording to the mean T389/S6K ratios,

Deleted: 16
Deleted: and their wild-type binding partner (TSC1 or TSC2)

Deleted: TSC1-TSC2

Deleted: If the $\mathrm{v}$

Deleted: was

Deleted: protein

Deleted: , then it was evidence that

Deleted: un

Deleted:

Deleted: If the signal for the wild-type binding partner was significantly reduced compared to the corresponding signal for the wild-type complex then it was evidence that the variant was unable to stabilise the TSC1-TSC2 complex. We compared the signal for each variant with the corresponding signal for the wild-type protein (Figures 4B, 5A and 6A). We classified variants with a significantly lower mean signal than the corresponding wild-type protein $(\mathrm{p}<0.05$, paired t-test $)$ as unstable (

Deleted: 9 
not shown). Of the unstable TSC2 variants, 35/38 had been defined as pathogenic

according to the comparisons of the T389/S6K ratios. In the 3 remaining cases (TSC2

R1159L, TSC2 R1159Q and TSC2 R1772C), the variant inhibited S6K T389-

phosphorylation as effectively as wild-type TSC2, despite being detected at lower levels

(Figure 4A and C; see Discussion).

Deleted: 6

Finally, we compared the signals for wild-type TSC1 in the presence of the

different TSC2 variants (Figures $3 \mathrm{~B}$ and $4 \mathrm{~B}$ ), and the signals for wild-type TSC2 in the presence of the different TSC1 variants (Figure 2A). Coexpression of TSC2 stabilises

TSC1 [Nellist et al., 1999]. Therefore we classified TSC2 variants that were associated with a significantly reduced TSC 1 signal $(\mathrm{p}<0.05$, paired $\mathrm{t}$-test) and TSC1 variants that were associated with a significantly reduced TSC2 signal $(\mathrm{p}<0.05$, paired t-test) as destabilising. Three TSC1 variants, L93R, N198F199delinsI and M224R, were

associated with a significant reduction in the TSC2 signal (Figure 2A). In each case we had classified the variant as pathogenic due to a significantly increased T389/S6K ratio compared to wild-type TSC1 (Supporting Table $\underline{\mathbf{S}} 1$ ). Thirty-eight TSC2 variants were associated with a significant reduction in the TSC1 signal (Figures $3 \mathrm{~B}$ and $4 \mathrm{~B}$ ). We divided these variants into 2 groups. One group of 31 variants clustered within the Nterminal half of TSC2 (amino acids 98 - 897), while a smaller group of 7 variants clustered close to the C-terminus (amino acids 1525 - 1773). In all 38 cases we had classified the variant as pathogenic due to a significantly increased T389/S6K ratio compared to wild-type TSC1-TSC2 (Supporting Tables $\underline{\mathrm{S}} 2$ and $\underline{\mathrm{S}} 3$ ).

\section{Prediction Analysis}

We investigated the possibility that the nucleotide changes corresponding to variants that did not affect TSC1-TSC2 function in our assay, disrupted TSC1 or TSC2 
splicing. We analysed the TSC1 and TSC2 nucleotide changes using 3 different splicesite prediction programs and identified 8 variants ( $5 T S C 1$ and $3 T S C 2)$ that were predicted to cause splicing abnormalities (Supporting Tables $\underline{S} 1$ and $\underline{S} 2)$. In one case (TSC2 $\mathrm{c} .1235 \mathrm{~A}>\mathrm{T}$ ), this was confirmed by functional assessment of the predicted TSC2 splice variant, TSC2 412del8 (Figure 3, Supporting Figure $\mathrm{S}_{\S}$ and Supporting Table $\underline{S}_{2}$; [Jansen et al., 2008]).

Next, we investigated whether the functional assessments of the TSC1 and TSC2 variants were in agreement with the Sorting Intolerant From Tolerant (SIFT) amino acid substitution prediction method [Ng and Henikoff, 2006]. The SIFT algorithm combines information from the chemical structure of the individual amino acids and the evolutionary conservation of a protein to predict whether specific substitutions can be tolerated by the protein

SIFT analysis of TSC1 indicated that the N-terminal (amino acids 1 - 300) and C-terminal (amino acids 700 - 1164) regions were relatively intolerant to amino acid changes [Mozaffari et al., 2009]. All the TSC1 variants classified as pathogenic according to our functional assessment clustered within the substitution intolerant $\mathrm{N}$ terminal region (Supporting Table $\underline{S} 1$ ). SIFT predicted that $18 / 41$ (44\%) of the TSC1 missense changes would not be tolerated. In 36 cases (88\%), the SIFT prediction was consistent with the functional assessment. In 5 cases $_{2}$ R190C, R246K, R246T, H732Y and $\mathrm{R} 1097 \mathrm{H}_{e}$ SIFT predicted that the substitution would not be tolerated, while the functional assessment indicated that the amino acid changes were probably neutral. In the case of the R246K and R246T substitutions, splice site prediction analysis indicated that the corresponding nucleotide changes (c.737G >A and c. $737 \mathrm{G}>\mathrm{C}$ ) were likely to cause splicing errors. Similarly, although the K121R, G305R and G305W substitutions were tolerated by the SIFT analysis and were probably neutral according to the

Deleted: Overall, there was broad agreement between the SIFT predictions and our functional assessments for both the TSC 1 and TSC 2 variants. Nevertheless, there were sufficient exceptions to indicate that the results of SIFT and similar prediction algorithms should be treated with caution.
Deleted: s Deleted: 3 and 5 Deleted:
Deleted: (

Deleted: ) 
functional assessment, splice site analysis predicted that the corresponding nucleotide

individuals without TSC (http://www.lovd.nl/TSC1) and is unlikely to cause TSC,

consistent with the results of our functional assessment (Figure 2, Supporting Figure S1,

and Supporting Table $\underline{S} 1)$. However, this variant is associated with focal cortical

dysplasia type II [Lugnier et al., 2009]. Therefore, the SIFT result may still be accurate,

even though the H732Y substitution is not critical for TSC1 function in our assay. Due

to reduced amino acid sequence conservation at the C-terminus of TSC1, the SIFT

prediction for the TSC1 R1097H substitution was made with a low degree of

confidence, and is therefore not reliable (data not shown).

SIFT analysis of TSC2 indicated that amino acids 1 - 900 and 1500 - 1807, corresponding to the TSC1-binding domain and the GAP domain respectively, were intolerant of amino acid substitutions (Supporting Figure S5). In total, the SIFT

prediction and functional assessment were consistent for $77 \mathrm{TSC} 2$ variants

(80\%)(Supporting Tables $\underline{\mathrm{S}} 2$ and $\underline{\mathrm{S}} 3)$. SIFT tolerated $42 / 96(44 \%)$ of the TSC2 amino

acid substitutions subjected to functional testing. Fourteen $(31 \%)$ of these tolerated changes were classified as pathogenic according to the functional assessment. In addition, splice site analysis predicted that the TSC2 c.1118A >C (p.Q373P) variant that was tolerated by SIFT and classified as neutral according to the functional assessment, was likely to be a splice site mutation. Of the 54 substitutions that were not tolerated by SIFT, 5 were classified as neutral according to the functional assessment. For 2 of these, TSC2 c.1235A > T (p.E412V) and TSC2 c.1255C >T (p.P419S), splice site analysis predicted that the nucleotide changes would affect splicing. In summary, using a transfection-based immunoblot assay we classified 16/45 TSC1 variants (36\%) and 70/107 TSC2 variants (65\%) as pathogenic; and 29/45 
1

2

3

4

5

6

7

8

9

10

11

12

13

14

15

16

17

18

19

20

21

22

23

24

25

26

27

28

29

30

31

32

33

34

35

36

37

38

39

40

41

42

43

44

45

46

47

48

49

50

51

52

53

54

55

56

57

58

59

60

TSC1 variants (64\%) and 37/107 TSC2 variants (32\%) as probably neutral. In 8 cases, 5 TSC1 and $3 \mathrm{TSC} 2$, the variant was neutral according to the functional assessment, but splice site analysis predicted that the corresponding nucleotide change was likely to be a pathogenic splice site mutation. Of the 79 previously untested variants, we classified 43 (54\%) as pathogenic, including 5/19 TSC1 (26\%) and 38/60 TSC2 variants (63\%).

\section{Discussion}

Mutation analysis of individuals with, or suspected of having, a genetic disease facilitates the diagnosis, treatment and genetic counselling of those individuals and their families. However, in some cases it is not possible to determine from the genetic data whether an identified nucleotide change is disease-causing. Functional analysis of predicted protein variants provides an additional method for determining whether specific changes are pathogenic.

We have characterised the effects of 152 TSC1 and TSC2 amino acid substitutions and small in-frame insertions/deletions on the TSC1-TSC2 complex. Based on our functional assessment we classified $86(56 \%)$ of the changes as pathogenic. In $8(5 \%)$ cases where we did not detect an effect on protein function, the corresponding nucleotide change was predicted to cause splicing defects. In one case (TSC2 1235A $>$ T), we confirmed that the splicing defect resulted in the production of an inactive TSC2 variant [Janssen et al., 2008]. In the remaining 7 cases, additional RNA studies are required to confirm the predicted effects on splicing.

We tested 45 TSC1 variants, of which 42 were amino acid substitutions and 3 were in-frame insertion/deletion changes. In 4 cases we analysed multiple changes at the same codon. Sixteen variants were detected at significantly reduced levels compared 
to wild-type TSC1. In each case, TORC1 activity, as estimated from the ratio of T389 phosphorylated S6K to total S6K, was increased compared to the wild-type control and we classified these variants as pathogenic. Consistent with previous studies [Nellist et al., 2009, Mozaffari et al., 2009], all the variants that were detected at low levels by immunoblotting mapped to the TSC1 N-terminal region (amino acids 50 - 224) and had a distinct cytoplasmic localisation pattern compared to wild-type TSC1, confirming the importance of this region for TSC1 function, localisation and stability [HoogeveenWesterveld et al., 2010].

We tested 104 TSC2 variants, of which 95 were amino acid substitutions, 3 were small in-frame insertions ( 1 - 3 amino acids) and 6 were in-frame deletions (1 - 26 amino acids). In 12 cases we analysed multiple changes at the same codon. Fifty-five changes affected the N-terminal half of the protein (amino acids $1-900$ ), and 52 affected the C-terminal region (amino acids $901-1784)$. Twenty $(36 \%)$ of the changes Deleted: -one in the N-terminal region were unstable, and $31(56 \%)$ were associated with significantly Deleted: 8 reduced levels of TSC1, consistent with an important role for the TSC2 N-terminal region in binding and stabilising TSC1 [Li et al., 2004]. Eighteen (35\%) of the changes in the C-terminal region were unstable and 7 (13\%) were associated with significantly reduced levels of TSC1. The $7 \mathrm{C}$-terminal variants associated with reduced levels of TSC1 mapped between amino acids 1525 and 1729, suggesting that this region may also play a role in maintaining stable TSC1-TSC2 complexes.

For 3 TSC2 variants, R1159L, R1159Q and R1772C, the T389/S6K ratio was not significantly different from wild-type TSC1-TSC2, despite the fact that the TSC2 $\underline{\text { signals for these variants were reduced compared to wild-type TSC2. In a previous }}$ study we concluded that the R1772C variant was unlikely to be pathogenic because an individual with this variant and TSC had another TSC2 mutation [Nellist et al., 2008]. 
Furthermore, individuals with this variant and no signs of TSC have been identified (http://www.lovd.nl/TSC2). Therefore, we classified the TSC2 R1772C variant as probably neutral (Supporting Table S3). The R1159L and R1159Q variants were also classified as probably neutral because, despite the reduced signals, they were both able to inhibit S6K T389 phosphorylation as effectively as wild-type TSC1-TSC2. In the TSC2 LOVD, the R1159L variant is classified as unknown, while the R1159Q variant is classified as having no known pathogenicity because it was identified in a TSC patient with another mutation (http://www.lovd.nl/TSC2). Nevertheless, in vivo it is possible that the reduced stability of the R1159L, R1159Q and R1772C variants renders them less effective at inhibiting TORC1 activity. It would be useful to have additional assays to characterise these variants in more detail.

We compared our functional assessment with the predictions of the SIFT algorithm $[\mathrm{Ng}$ and Henikoff, 2006] and with the classifications listed in the TSC1 and TSC2 LOVD (http://www.lovd.nl/TSC1 and http://www.lovd.nl/TSC2) (Supporting Tables S1, S2 and S3). Overall, there was broad agreement (>80\%) between the SIFT predictions and our functional assessments for both the TSC1 and TSC2 variants. Nevertheless, there were sufficient exceptions to indicate that the results of SIFT and $\underline{\text { similar prediction algorithms should be treated with caution. In general there was also }}$ good agreement between the LOVD classifications and our functional assessment. According to the LOVD classifications, 29 variants had no known pathogenicity or were probably not pathogenic. We classified 27 (93\%) of these as probably neutral. There was strong disagreement for only one TSC1 variant (F216S) and one TSC2 variant (F615S). The TSC1 F216S variant was classified as probably not pathogenic in the TSC1 LOVD because it was identified in a TSC patient and their apparently unaffected parent, but is a pathogenic change according to our functional assessment. 
Clinical re-evaluation prompted by our findings, showed that the parent has signs of TSC, and therefore the TSC1 c.647T>C (p.F216S) variant co-segregates with disease in this family. The status of the variant in the TSC1 LOVD has now been updated to pathogenicity unknown, in line with current LOVD definitions. The TSC2 F615S substitution was classified as having no known pathogenicity in the TSC2 LOVD, but is a pathogenic change according to our functional assessment, consistent with our previous studies [Nellist et al., 2001; Nellist et al., 2005]. The TSC2 c.1844T>C (p.F615S) variant was identified in an individual with TSC and once in a control group of >100 apparently unaffected individuals [Gilbert et al., 1998]. However, as far as we are aware, the variant has not been detected in any other individuals. The status of this variant in the TSC2 LOVD has now been updated to pathogenicity unknown.

Forty-nine of the variants tested were classified as pathogenic or probably pathogenic in the TSC1 and TSC2 LOVD. Forty-one (84\%) of these were pathogenic according to our functional assessment. In 5 cases where the functional assessment indicated that the TSC1 or TSC2 variant was probably a neutral change, splice site analysis indicated that the corresponding nucleotide change was likely to be a splice site mutation. Therefore there was strong disagreement between the functional assessment and the LOVD classification for only 3 TSC2 variants, K599M, R951S and L1773I. The TSC2 K599M substitution is classified as pathogenic in the TSC2 LOVD because it was reported to be a de novo change [Niida et al., 1999] that reduced the TSC2dependent inhibition of 4E-BP1 phosphorylation in vitro [Tee et al., 2002]. However, consistent with our previous studies [Nellist et al., 2001; Nellist et al., 2005], in our assay, the K599M substitution did not affect TSC1 or TSC2 stability and inhibited S6K T389 phosphorylation as effectively as wild-type TSC2. The status of this variant in the TSC2 LOVD has now been changed to pathogenicity unknown as it is not clear why 
1

2

3

4

5

6

7

8

9

10

11

12

13

14

15

16

17

18

19

20

21

22

23

24

25

26

27

28

29

30

31

32

33

34

35

36

there is a discrepancy between the different reports. The TSC2 R951S substitution was classified as probably pathogenic in the TSC2 LOVD, but is probably neutral according to our functional assessment. No additional family data was available for this variant and therefore according to the current LOVD classification criteria, the variant should be classified as pathogenicity unknown. Codon 951 is encoded by the alternatively spliced exon 25 of the TSC2 gene [Xu et al., 1995]. Very few pathogenic changes have been identified in this exon (http://www.lovd.nl/TSC2), and complete removal of this exon did not affect TSC2 function in our assay (M. Wentink, M. Nellist, unpublished observations). Finally, the TSC2 L1773I variant was classified as probably pathogenic in the TSC2 LOVD, but is probably neutral according to our functional assessment. Although the TSC2 c.5386C >A (p.L1773I) is listed as a de novo change, there is no record that paternity testing was performed, and it is possible that the TSC 2 c.5386C $>\mathrm{A}$ (p.L1773I) variant is a rare neutral variant.

Although in most cases it was clear whether a variant inhibited S6K T389 phosphorylation or not, for a few variants we noticed that there was more interexperiment variation. Some variants appeared more effective at inhibiting S6K T389 phosphorylation in one experiment compared to the next. An example of this variation is shown in Supporting Figure S6. Furthermore, in some cases, the signal of the variant $\underline{\text { itself, or its binding partner, was quite variable, even though the transfection efficiency, }}$ as assessed by the S6K signal, was constant. For example, the mean signals for TSC2 in the presence of the TSC1 I76N and L93R variants are approximately equal (Figure 2A; Supporting Table S1). However, because the TSC2 signal showed more interexperiment variation in the presence of the $176 \mathrm{~N}$ variant, it was not significantly $\underline{\text { different from the wild-type signal, while the TSC2 signal in the presence of the L93R }}$ variant was significantly reduced compared to the wild-type. For this reason, it is 
possible that our assay missed some variants that are slightly less active or stable than wild-type TSC1 or TSC2. Therefore, although we could clearly distinguish variants that were less active than wild-type TSC1 and TSC2, it was more difficult to be certain that variants that were indistinguishable from wild-type in our assay were neutral variants, and not pathogenic. Nevertheless, we classified 29 TSC1 and 37 TSC2 variants as probably neutral because they were able to inhibit S6K T389 phosphorylation as effectively as wild-type TSC1-TSC2 in our assay. In the majority of cases these variants are most likely to be rare, neutral variants that do not cause TSC. However, we could not exclude the possibility that some variants have sufficient activity in our overexpression system to inhibit TORC1, while in vivo they may be inactive or unstable.

Furthermore, we did not investigate any other TORC1-dependent or -independent effects of TSC1 or TSC2. Some variants might affect other TSC1-TSC2 functions than the TSC1-TSC2 interaction or TORC1 signalling to S6K. Additional analysis of the variants classified here as probably neutral is necessary to determine whether these variants affect other TSC1-TSC2 functions.

Despite these notes of caution, we conclude that our functional assessment has provided important insight into whether specific TSC1 and TSC2 variants are pathogenic. In summary, we classified 152 different TSC1 and TSC2 variants using a transfection-based immunoblot assay that distinguished pathogenic TSC1 and TSC2 variants from probable neutral variants according to whether there was increased S6KT389 phosphorylation. Based on this functional assessment, 86 variants were classified as pathogenic and 67 as probably neutral, providing useful information for genetic counselling in the individuals carrying these variants.

\section{Deleted: II}

A

Deleted: W

Deleted: In 3 cases, TSC2 R1159L, R1159Q and R1772C, the T389/S6K ratio was not significantly different from wild-type TSC1-TSC2, despite the fact that the TSC2 signals for these variants were reduced compared to wild-type

TSC2. In a previous study we concluded that the $\mathrm{R} 1772 \mathrm{C}$ variant was unlikely to be pathogenic because an individual with this variant and TSC had another TSC2 mutation [Nellist et al., 2008].

Furthermore, individuals with this variant and no signs of TSC have been identified (http://www.lovd.nl/TSC2). Therefore, we classified the TSC2 R1772C variant as probably neutral (Table 3 ). The antiserum used to detect the TSC2 variants binds epitopes encoded by the last exon of TSC2, which includes codon 1772 (M. Wentink, M. Nellist; unpublished results) and it is possible that the $\mathrm{R} 1772 \mathrm{C}$ substitution reduces the affinity of the antiserum for TSC2,

resulting in a lower immunoblot signal. The R1159L and R1159Q variants were also classified as probably neutral because, despite the reduced signals, they were both able to inhibit S6K T389 phosphorylation as effectively as wildtype TSC1-TSC2. In the LOVD TSC2 database, the R1159L variant is classified as unknown, while the R1159Q variant is classified as having no known

pathogenicity because it was identified in a TSC patient with another mutation (http://www.lovd.nl/TSC2). Nevertheless, in vivo it is possible that the reduced stability of the R1159L and R1159Q variants renders them unable to

effectively inhibit TORC1 activity and we could therefore not completely exclude the possibility that these variants are pathogenic. For this reason it would be useful to have additional assays to characterise these variants in more detail.d[ Deleted: i 


\author{
Acknowledgments \\ Financial support was provided by the U.S. Department of Defense \\ Congressionally-Directed Medical Research Program (grant \#TS060052), the Michelle \\ Foundation and the Tuberous Sclerosis Alliance. The authors report no conflicts of \\ interest.
}




\section{References}

Au K-S, Williams AT, Roach ES, Batchelor L, Sparagana SP, Delgado MR, Wheless JW, Baumgartner JE, Roa BB, Wilson CM, Smith-Knuppel TK, Cheung MY,

Whittemore VH, King TM, Northrup H. 2007. Genotype/phenotype correlation in 325 individuals referred for a diagnosis of tuberous sclerosis complex in the United States. Genet Med 9:88-100.

Coevoets R, Arican S, Hoogeveen-Westerveld M, Simons E, van den Ouweland A, Halley D, Nellist M 2009 A reliable cell-based assay for testing unclassified TSC2 gene variants. Eur J Hum Genet 17:301-310.

Dabora SL, Jozwiak S, Franz DN, Roberts PS, Nieto A, Chung J, Choy YS, Reeve MP, Thiele E, Egelhoff JC, Kasprzyk-Obara J, Domanska-Pakiela D, Kwiatkowski DJ. 2001. Mutational analysis in a cohort of 224 tuberous sclerosis patients indicates increased severity of $T S C 2$, compared with $T S C 1$, disease in multiple organs. Am J Hum Genet 68:64-80.

Daumke O, Weyand M, Chakrabarti PP, Vetter IR, Wittinghofer A. 2004. The GTPaseactivating protein Rap1GAP uses a catalytic asparagine. Nature 429:197-201.

European Chromosome 16 Tuberous Sclerosis Consortium. 1993 Identification and characterization of the tuberous sclerosis gene on chromosome 16. Cell 75:1305-1315.
Deleted: Adachi H, Igawa M, Shiina $\mathrm{H}$, Urakami S, Shigeno K, Hino O. 2003. Human bladder tumors with 2-hit mutations of tumor suppressor gene TSC1 and decreased expression of p27. J. Urol. 170:601-604.II

II

\section{Deleted: II}

Benit P, Kara-Mostefa A, Hadj-Rabia S, Munnich A, Bonnefont JP. 1999. Protein truncation test for screening hamartin gene mutations and report of new disease-causing mutations. Hum Mutat $14: 428-432$.II

II

Choi JE, Chae JH, Hwang YS, Kim KJ. 2006. Mutational analysis of TSCl and TSC2 in Korean patients with tuberous sclerosis complex. Brain Dev 28:440446.II 
Hoogeveen-Westerveld M, Exalto C, Maat-Kievit A, van den Ouweland A, Halley D,

Nellist M. 2010. Analysis of TSC1 truncations defines regions involved in TSC1

stability, aggregation and interaction. Biochim Biophys Acta 1802:774-781.

Inoki K, Li Y, Zhu T, Wu J, Guan K-L. 2002. TSC2 is phosphorylated and inhibited by Akt and suppresses mTOR signalling. Nat Cell Biol 4:648-657.

Inoki K, Guan K-L. 2009. Tuberous sclerosis complex, implication from a rare genetic disease to common cancer treatment. Hum Mol Genet 18:R94-R100.

Jansen FE, Braams O, Vincken KL, Algra A, Anbeek P, Jennekens-Schinkel A, Halley

D, Zonnenberg BA, van den Ouweland A, van Huffelen AC, van Nieuwenhuizen O,

Nellist M. 2008. Overlapping neurologic and cognitive phenotypes in patients with

TSC1 or TSC2 mutations. Neurology 70:908-915.

Jones AC, Shyamsundar MM, Thomas MW, Maynard J, Idziaszczyk S, Tomkins S,

Sampson JR, Cheadle JP. 1999. Comprehensive mutation analysis of TSC1 and TSC2,

Deleted: Hodges AK, Li S, Maynard J, Parry L, Braverman R, Cheadle JP, DeClue JE, Sampson JR. 2001. Pathological mutations in TSCl and TSC2 disrupt the interaction between hamartin and tuberin. Hum Mol Genet 10:28992905. II

II

Deleted: Huang J, Dibble CC, Matsuzaki M, Manning BD. 2008. The TSC1-TSC2 complex is required for proper activation of mTOR complex 2 . Mol Cell Biol 28:4104-4115.I II Hung CC, Su YN, Chien SC, Liou HH, Chen CC, Chen PC, Hsieh CJ, Chen CP, Lee WT, Lin WL, Lee CN. 2006. Molecular and clinical analyses of 84 patients with tuberous sclerosis complex. BMC Med Genet 7:72.II II

Deleted: Jansen AC, Sancak O, D'Agostino MD, Badhwar A, Roberts P, Gobbi G, Wilkinson R, Melanson D, Tampieri D, Koenekoop R, Gans M, Maat-Kievit A, Goedbloed M, van den Ouweland AMW, Nellist M, Pandolfo M, McQueen M, Sims K, Thiele EA, Dubeau $\mathrm{F}$, Andermann F, Kwiatkowski DJ, Halley DJJ, Andermann E. 2006.

Unusually mild tuberous sclerosis phenotype is associated with TSC2 R905Q mutation. Ann Neurol. 60:528539. II

II 
and phenotypic correlations in 150 families with tuberous sclerosis. Am J Hum Genet 64:1305-1315.

Kwiatkowski DJ, Zhang H, Bandura JL, Heiberger KM, Glogauer M, el-Hashemite N, Onda H. 2001. A mouse model of TSC1 reveals sex-dependent lethality from liver hemangiomas, and up-regulation of p70S6 kinase activity in Tsc1 null cells. Hum Mol Genet 11:525-534.

Li Y, Corradetti MN, Inoki K, Guan J-L. 2003. TSC2: filling the GAP in the mTOR signaling pathway. Trends Biochem Sci 28:573-576.

Li Y, Inoki K, Guan K-L. 2004. Biochemical and functional characterization of small GTPase Rheb and TSC2 GAP activity. Mol Cell Biol 24:7965-7975.

Lugnier C, Majores M, Fassunke J, Pernhorst K, Niehusmann P, Simon M, Nellist M, Schoch S, Becker A. 2009. Hamartin variants that are frequent in focal dysplasias and cortical tubers have reduced tuberin binding and aberrant subcellular distribution in vitro. J Neuropathol Exp Neurol 68:1136-1146.

Mozaffari M, Hoogeveen-Westerveld M, Kwiatkowski D, Sampson J, Ekong R, Povey S, den Dunnen JT, van den Ouweland A, Halley D, Nellist M. 2009. Identification of a region required for TSC1 stability by functional analysis of TSC1 missense mutations Deleted: Mayer K, Goedbloed M, van Zijl K, Nellist M, Rott HD. 2004. Characterisation of a novel TSC2 missense mutation in the GAP related domain associated with minimal clinical manifestations of tuberous sclerosis. J Med Genet 41:64.II II found in individuals with tuberous sclerosis complex. BMC Med Genet 10:88. 
Nellist M, van Slegtenhorst MA, Goedbloed M, van den Ouweland AMW, Halley DJJ, van der Sluijs P. 1999. Characterization of the cytosolic tuberin-hamartin complex: tuberin is a cytosolic chaperone for hamartin. J Biol Chem 274:35647-35652.

Nellist M, Verhaaf B, Goedbloed MA, Reuser AJJ, van den Ouweland AMW, Halley DJJ. 2001. TSC2 missense mutations inhibit tuberin phosphorylation and prevent formation of the tuberin-hamartin complex. Hum Molec Genet 10:2889-2898.

Nellist M, Sancak O, Goedbloed MA, Rohe C, van Netten D, Mayer K, TuckerWilliams A., van den Ouweland AMW, Halley DJJ. 2005. Distinct effects of single amino acid changes to tuberin on the function of the tuberin-hamartin complex. Eur $\mathbf{J}$ Hum Genet 13:59-68.

Nellist M, Sancak O, Goedbloed M, Adriaans A, Wessels M, Maat-Kievit A, Baars M, Dommering C, van den Ouweland A, Halley D. 2008. Functional characterisation of the TSC1-TSC2 complex to assess multiple TSC2 variants identified in single families affected by tuberous sclerosis complex. BMC Med Genet 9:10.

Nellist M, van den Heuvel D, Schluep D, Exalto C, Goedbloed M, Maat-Kievit A, van Essen T, van Spaendonck-Zwarts K, Jansen F, Helderman P, Bartalini G, Vierimaa O, Penttinen M, van den Ende J, van den Ouweland A, Halley D. 2009. Missense mutations to the TSCl gene cause tuberous sclerosis complex. Eur J Hum Genet $17: 319-328$. 
Ng PC, Henikoff S. 2006. Predicting the effects of amino acid substitutions on protein function. Ann Rev Genomics Hum Genet 7:61-80.

Niida Y, Lawrence-Smith N, Banwell A, Hammer E, Lewis J, Beauchamp RL, Sims K, Ramesh V, Ozelius L. 1999. Analysis of both TSC1 and TSC2 for germline mutations in 126 unrelated patients with tuberous sclerosis. Hum Mutat 14:412-422.

Sancak O, Nellist M, Goedbloed M, Elfferich P, Wouters C, Maat-Kievit A, Zonnenberg B, Verhoef S, Halley D, van den Ouweland A. 2005 Mutational analysis of the TSC1 and TSC2 genes in a diagnostic setting: genotype-phenotype correlations and comparison of diagnostic DNA techniques in tuberous sclerosis complex. Eur J Hum Genet 13:731-741.

van Slegtenhorst M, de Hoogt R, Hermans C, Nellist M, Janssen B, Verhoef S, Lindhout D, van den Ouweland A, Halley D, Young J, Burley M, Jeremiah S,

Woodward K, Nahmias J, Fox M, Ekong R, Wolfe J, Povey S, Osborne J, Snell RG, Cheadle JP, Jones AC, Tachataki M, Ravine D, Sampson JR, Reeve MP, Richardson P, Wilmer F, Munro C, Hawkins TL, Sepp T, Ali JBM, Ward S, Green AJ, Yates JRW, Short MP, Haines JH, Jozwiak S, Kwiatkowska J, Henske EP, Kwiatkowski DJ. 1997. Identification of the tuberous sclerosis gene TSC1 on chromosome 9q34. Science 277: $805-808$.

van Slegtenhorst M, Nellist M, Nagelkerken B, Cheadle J, Snell R, van den Ouweland A, Reuser A, Sampson J, Halley D, van der Sluijs P. 1998. Interaction between hamartin and tuberin, the TSC1 and TSC2 gene products. Hum Mol Genet 7:1053-1057.

Deleted: O'Connor SE, Kwiatkowsk Huttenlocher PR. 2003. A family with seizures and minor features of tuberous sclerosis and a novel TSC2 mutation. Neurology 61:409-412.II

II

Qin W, Kozlowski P, Taillon BE, Bouffard P, Holmes AJ, Janne P, Camposano S, Thiele E, Franz D, Kwiatkowski DJ. 2010a. Ultra deep sequencing detects a low rate of mosaic mutations in Tuberous Sclerosis Complex. Hum Genet 127:573-582.II II

Qin W, Chan JA, Vinters HV, Mathern GW, Franz DN, Taillon BE, Bouffard P, Kwiatkowski DJ. 2010b. Analysis of TSC cortical tubers by deep sequencing of TSC1, TSC2 and KRAS demonstrates that small second-hit mutations in these genes are rare events. Brain Pathol doi:10.1111/j.1750-3639.2010.00416.x.II II

Ramantani G, Niggemann P, Hahn G, Nake A, Fahsold R, Lee-Kirsch MA. 2008. Unusual radiological presentation of tuberous sclerosis complex with leptomeningeal angiomatosis associated with a hypomorphic mutation in the TSC2 gene. J Child Neurol 24:333-337.II

II

Rendtorff ND, Bjerregaard B, Frodin M Kjaergaard S, Hove H, Skovby F, Brondum-Nielsen K, Schwartz M. 2005. Analysis of 65 tuberous sclerosis complex (TSC) patients by TSC 2 DGGE, TSC1/TSC2 MLPA, and TSC1 longrange PCR sequencing, and report of 28 II 
Tee AR, Fingar DC, Manning BD, Kwiatkowski DJ, Cantley LC, Blenis J. 2002.

Tuberous sclerosis complex-1 and -2 gene products function together to inhibit mammalian target of rapamycin (mTOR)-mediated downstream signaling. Proc Natl Acad Sci USA 99:13571-13576.

de Vries P, Howe CJ. 2007. The tuberous sclerosis complex proteins - a GRIPP on cognition and neurodevelopment. Trends Mol Med 13:319-326.

Xu L, Sterner C, Maheshwar MM, Wilson PJ, Nellist M, Short PM, Haines JL, Sampson JR, Ramesh V. 1995. Alternative splicing of the tuberous sclerosis 2 (TSC2) gene in human and mouse tissues. Genomics 27:475-480.

Zhang H, Cicchetti G, Onda H, Koon HB, Asrican K, Bajraszewski N, Vazquez F, Carpenter CL, Kwiatkowski DJ. 2003. Loss of Tsc1/Tsc2 activates mTOR and disrupts PI3K-Akt signaling through downregulation of PDGFR. J Clin Invest 112:1223-1233. 
Figure 1: Overview of the TSC1 and TSC2 variants analysed as part of this study.

Amino acid variants are numbered as originally described [van Slegtenhorst et al., 1997;

European Chromosome 16 Tuberous Sclerosis Consortium, 1993] (Genbank

AF013168.1; GI: 2331280 (TSC1) and X75621; GI:450351 (TSC2)) and according to

the amino acid sequences encoded by the expression constructs used in this study. The

initiation codon is codon 1.

(A) TSC1 variants. The positions of the TSC1 variants analysed as part of this study are indicated relative to the coding exons $(3-23)$ of the TSC1 gene.

(B) Variants mapping to the N-terminal half of TSC2 (amino acids 1 - 900). The positions of the variants are indicated relative to exons $1-23$ of the TSC2 gene.

(C) Variants mapping to the C-terminal half of TSC2 (amino acids 901 - 1784). The positions of the variants are indicated relative to exons 23 - 41 of the TSC 2 gene. The alternatively spliced exons 25 and 31 are shown in grey and the position of the GAP domain, corresponding to exon 37 , is shown in black. The amino acids encoded by exon 31 were not present in the TSC2 expression constructs used in this study.

Figure 2: Functional assessment of the TSC1 variants. The signals for TSC2, TSC1, total S6K (S6K) and T389-phosphorylated S6K (T389) were determined per variant, relative to the wild-type control (TSC1) in at least 4 independent transfection experiments. The mean signals are shown for each variant. Error bars represent the standard error of the mean; variants that were significantly different from the wild-type control (TSC1) are indicated with an asterisk. The signals from cells expressing exogenous TSC2 and S6K only, and no exogenous TSC1, are also shown (TSC2).

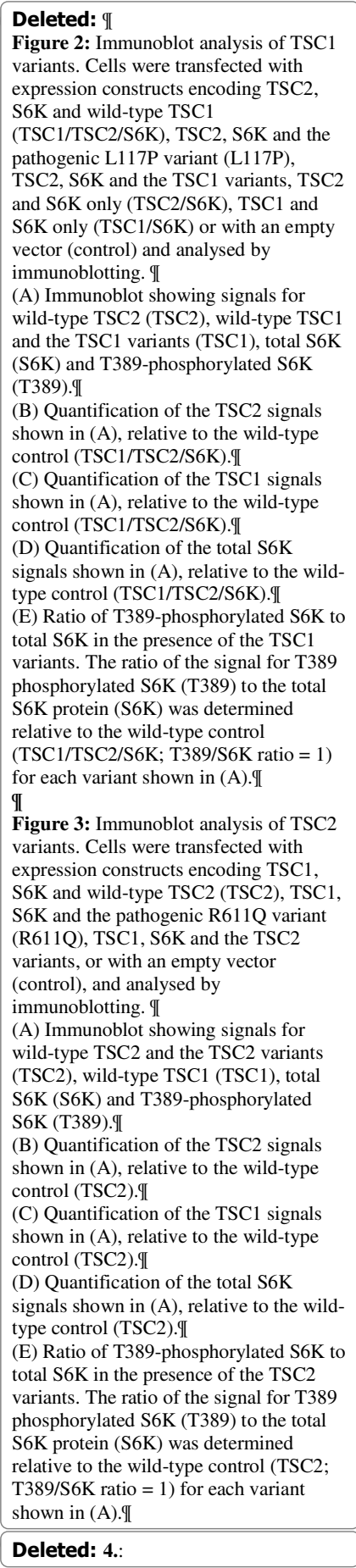

Deleted: II

(TSC1/TSC2/S6K), TSC2, S6K and the

pathogenic L117P variant (L117P), and $56 \mathrm{~K}$ only (TSC2/S6K), TSC1 and

S6K only (TSC1/S6K) or with an empty vector (control) and analysed by

mmunoblotting.

wild-type TSC2 (TSC2), wild-type TSC

(S6K) and variants (TSC1), total S6K

(T389).I 1389-phosphorylated S6K

B) Quantification of the TSC2 signal

(C) Quantification of the TSC1 signals shown in (A), relative to the wild-type control (TSC1/TSC2/S6K) type control (TSC1/TSC2/S6K).

(E) Ratio of T389-phosphorylated S6K total S6K in the presence of the TSC

phosphorylate of the signal for T389

(TSC1/TSC2/S6K; T389/S6K ratio = 1)

for each variant shown in (A).II

Figure 3: Immunoblot analysis of TSC2 variants. Cells were transfected with expression constructs encoding TSC 1 , S6K and wild-type TSC2 (TSC2), TSC1 (R611Q), TSC1, S6K and the TSC2

variants, or with an empty vector

(control), and analysed by

and T389-phosphorylated

B) Quantification of the TSC2 signals

(C) Quantification of the TSC1 signals shown in (A), relative to the wild-type control (TSC2).

signals shown in (A), relative to the wild-

type control (TSC2). Il

total $\mathrm{S} 6 \mathrm{~K}$ in the presence of the TSC2

variants. The ratio of the signal for T389 S6K prorylated S6K (T389) to the to

relative to the wild-type control (TSC2;

shown in (A).II 
1

(A) Mean TSC2 signals in the presence of the TSC1 variants, relative to wild-type TSC1-TSC2 $($ TSC1; TSC2 signal $=1)$.

(B) Mean signals for the TSC1 variants, relative to wild-type TSC1 (TSC1; TSC1 signal $=1)$.

(C) Mean T389/S6K ratios for the TSC1 variants, relative to wild-type TSC1-TSC2 $(\mathrm{TSC} 1 ; \mathrm{T} 389 / \mathrm{S} 6 \mathrm{~K}$ ratio $=1)$.

(D) Mean total S6K signals in the presence of the TSC1 variants, relative to wild-type TSC1-TSC2 (TSC1; S6K signal = 1).

Figure 3: Functional assessment of the TSC2 variants mapping to the N-terminal half of TSC2 (amino acids 1 - 900). The signals for TSC2, TSC1, total S6K (S6K) and T389-phosphorylated S6K (T389) were determined per variant, relative to the wild-type control (TSC2) in at least 4 independent transfection experiments. The mean signals are shown for each variant. Error bars represent the standard error of the mean; variants that were significantly different from the wild-type control (TSC2) are indicated with an asterisk.

(A) Mean signals for the TSC2 variants, relative to wild-type TSC1-TSC2 (TSC2; TSC2 signal =1).

(B) Mean TSC1 signals in the presence of the TSC2 variants, relative to wild-type TSC1-TSC2 $($ TSC2; TSC1 signal $=1)$.

(C) Mean T389/S6K ratios for the TSC2 variants, relative to wild-type TSC1-TSC2 $(\mathrm{TSC} 2 ; \mathrm{T} 389 / \mathrm{S} 6 \mathrm{~K}$ ratio $=1)$.

(D) Mean total S6K signals in the presence of the TSC2 variants, relative to wild-type TSC1-TSC2 (TSC2; S6K signal = 1). 
Figure 4: Functional assessment of the TSC2 variants mapping to the C-terminal half of Deleted: 6.: TSC2 (amino acids 901 - 1784). The signals for TSC2, TSC1, total S6K (S6K) and T389-phosphorylated S6K (T389) were determined per variant, relative to the wild-type control (TSC2) in at least 4 independent transfection experiments. The mean signals are shown for each variant. Error bars represent the standard error of the mean; variants that were significantly different from the wild-type control (TSC2) are indicated with an asterisk.

(A) Mean signals for the TSC2 variants, relative to wild-type TSC2 (TSC2; TSC2 signal $=1$ ).

(B) Mean TSC1 signals in the presence of the TSC2 variants, relative to wild-type TSC1-TSC2 (TSC2; TSC1 signal = 1).

(C) Mean T389/S6K ratios for the TSC2 variants, relative to wild-type TSC1-TSC2 $(\mathrm{TSC} 2 ; \mathrm{T} 389 / \mathrm{S} 6 \mathrm{~K}$ ratio $=1)$.

(D) Mean total S6K signals in the presence of the TSC2 variants, relative to wild-type TSC1-TSC2 (TSC2; S6K signal = 1). 


\section{Figure 1}

A

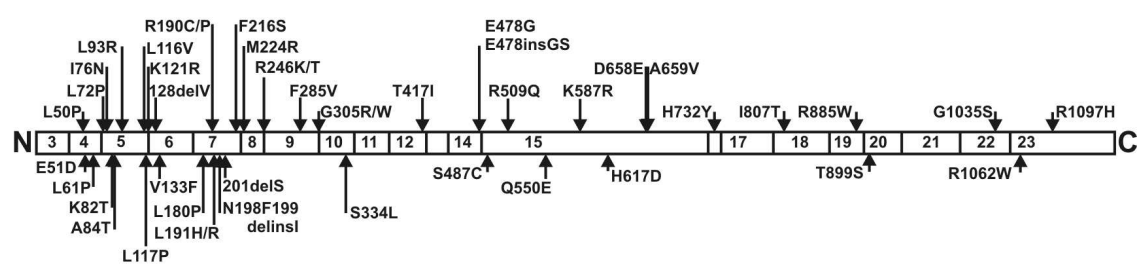

B
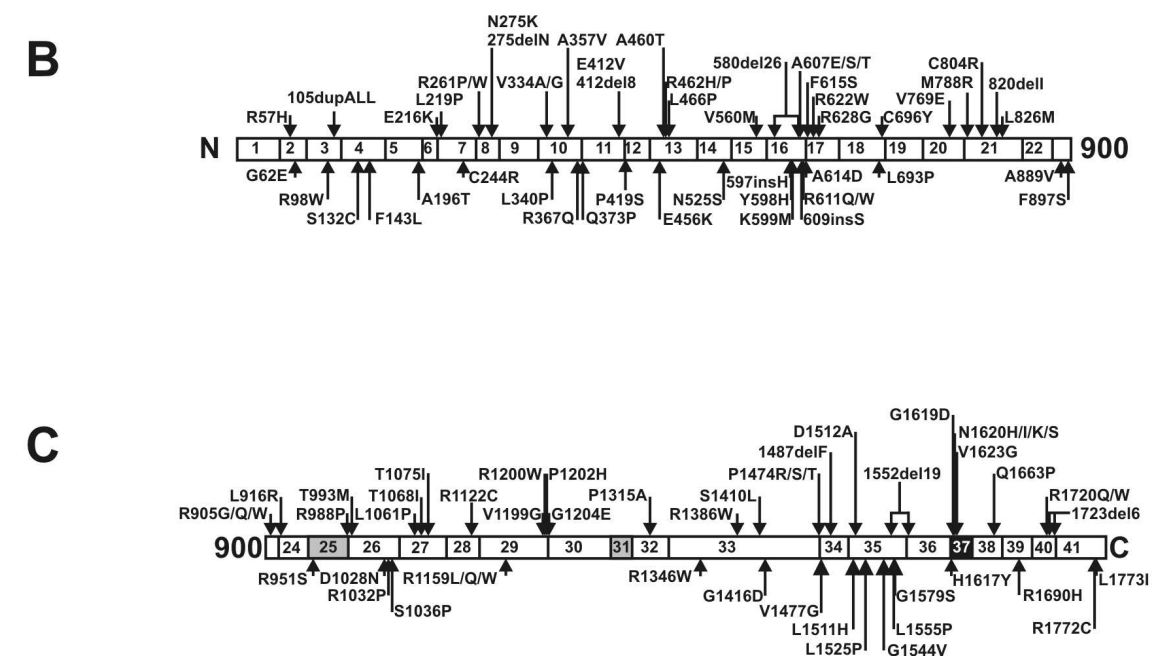

$168 \times 151 \mathrm{~mm}(300 \times 300$ DPI $)$

John Wiley \& Sons, Inc. 
Figure 2

A

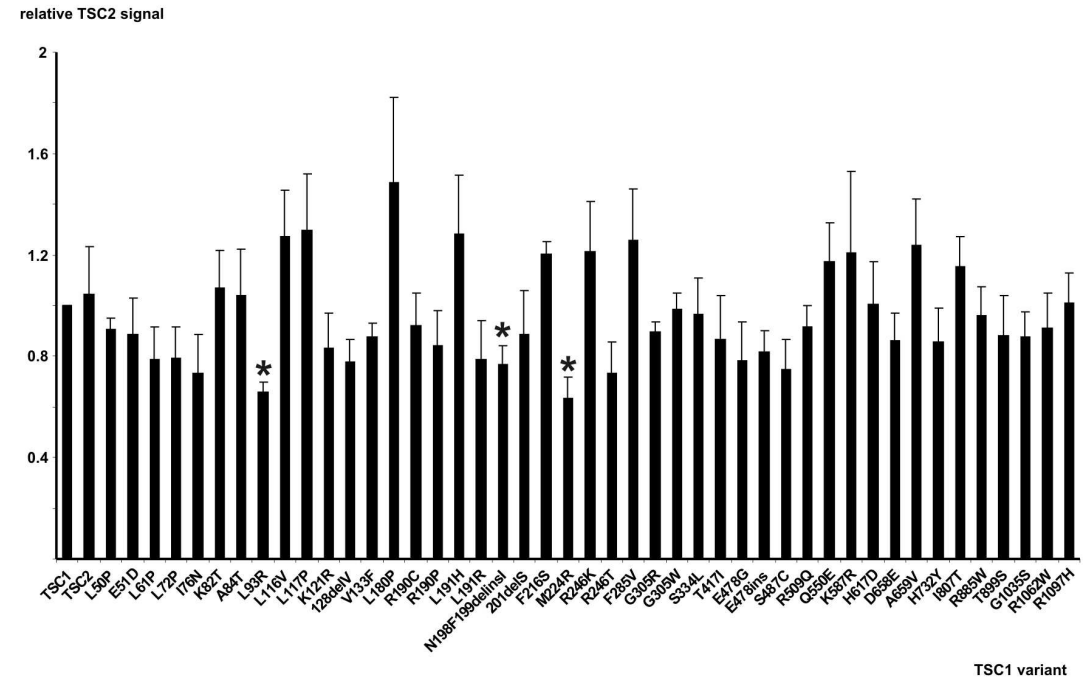

B relative TSC1 signal

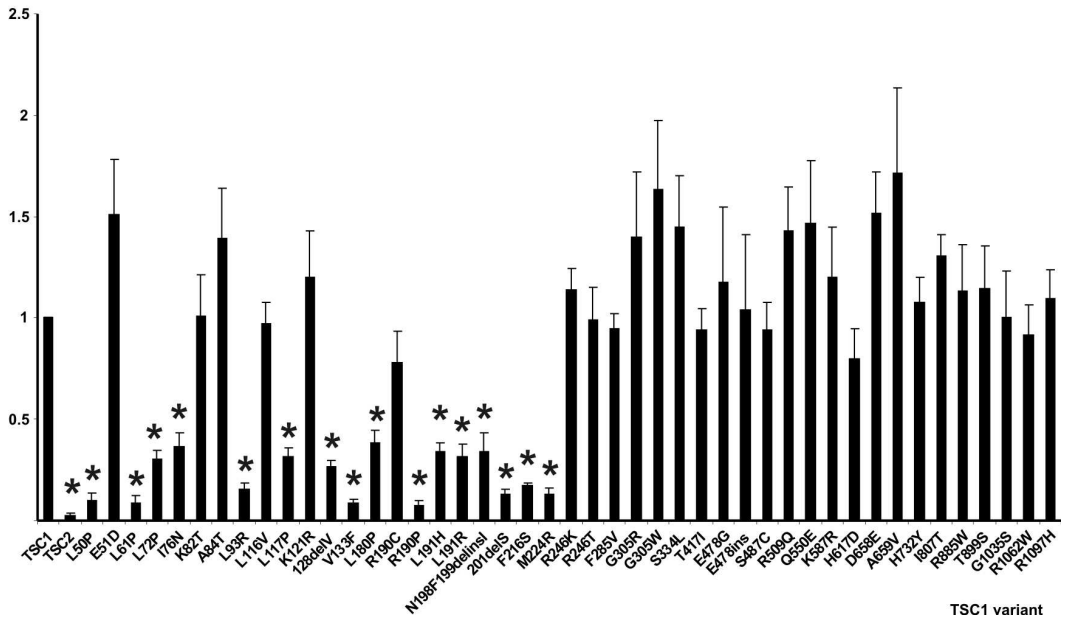

$160 \times 217 \mathrm{~mm}(300 \times 300$ DPI $)$

John Wiley \& Sons, Inc. 
Figure 2
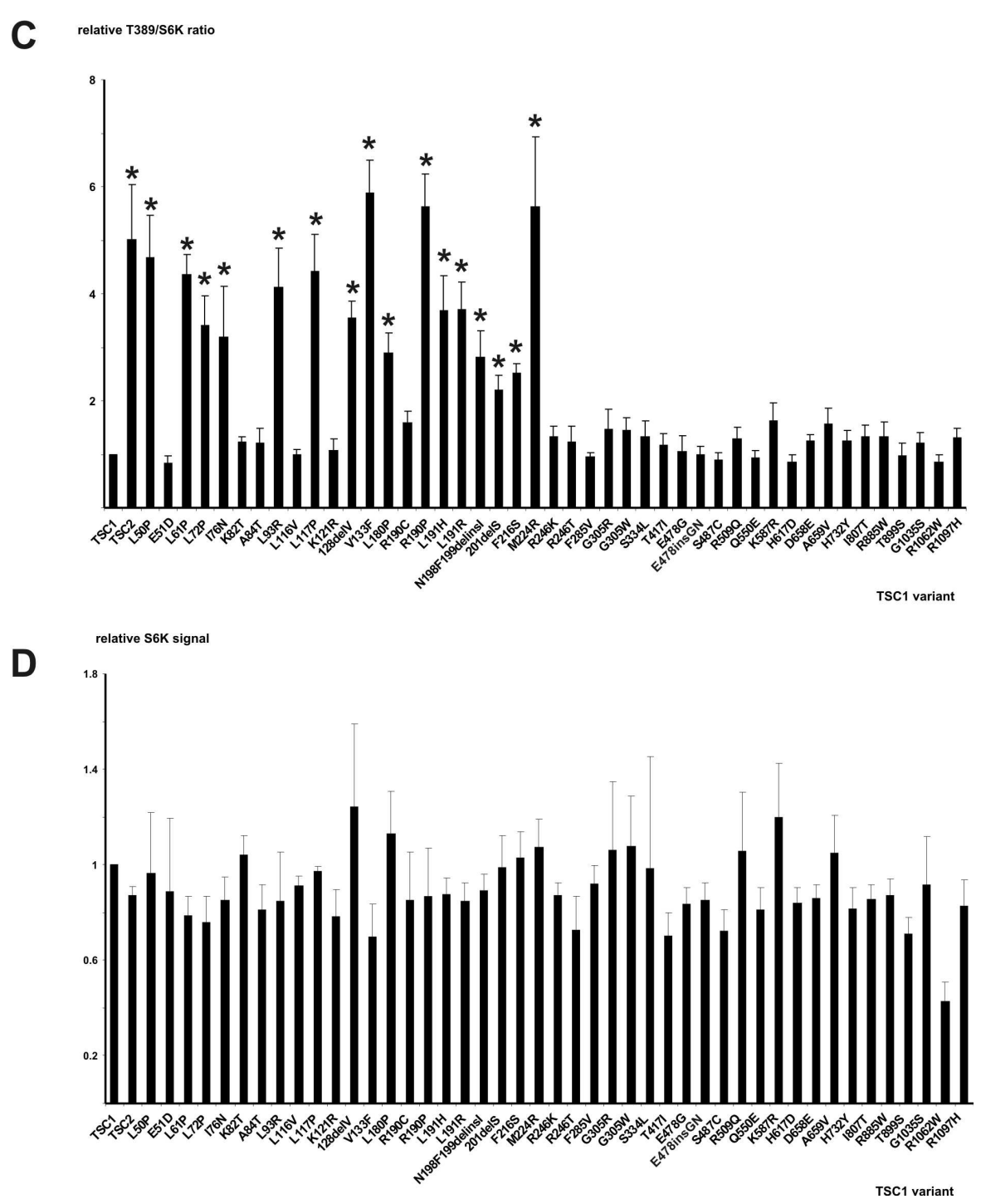

$159 \times 213 \mathrm{~mm}(300 \times 300$ DPI $)$

John Wiley \& Sons, Inc. 
Figure 3
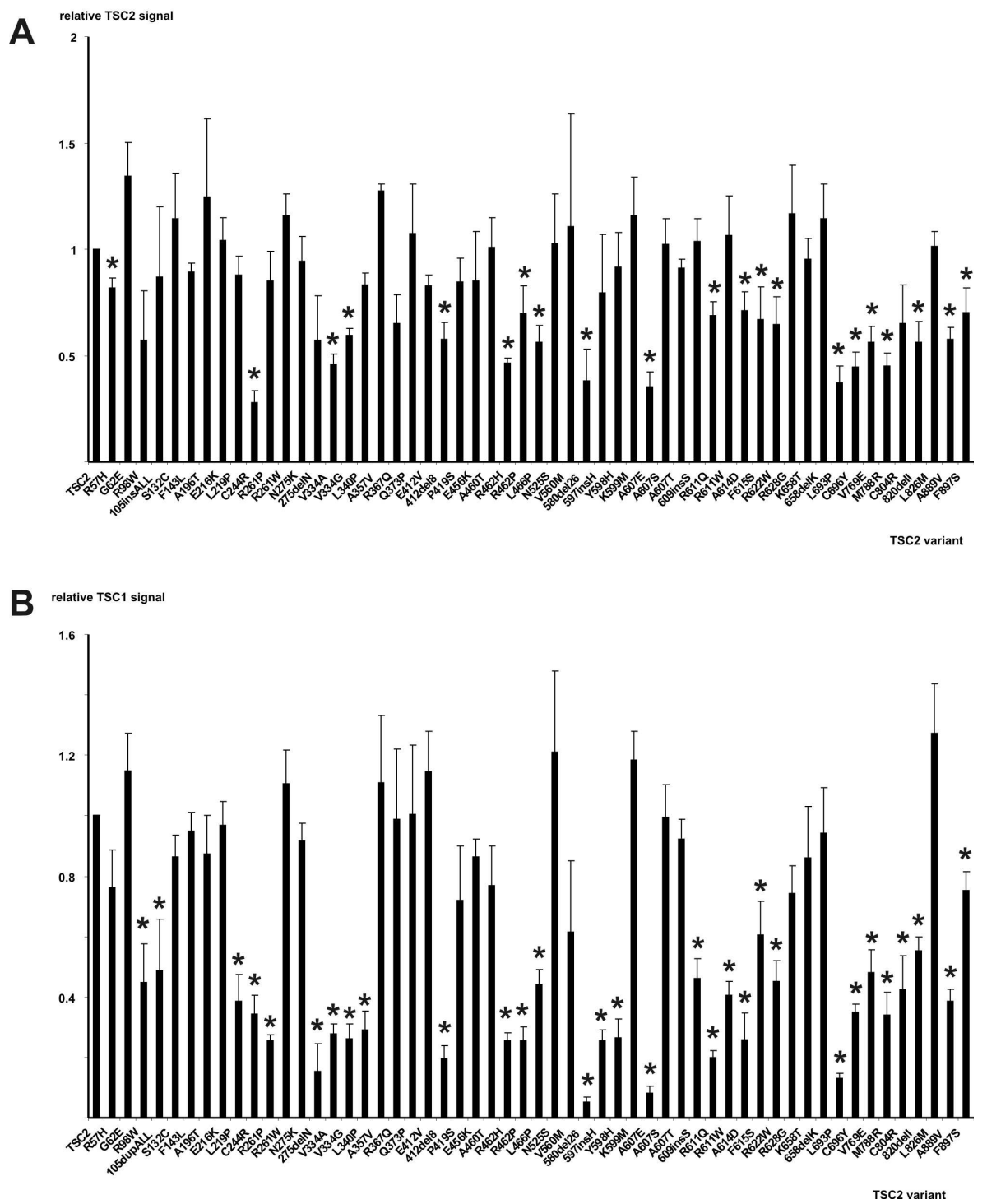

$170 \times 227 \mathrm{~mm}(300 \times 300 \mathrm{DPI})$

John Wiley \& Sons, Inc. 
Figure 3
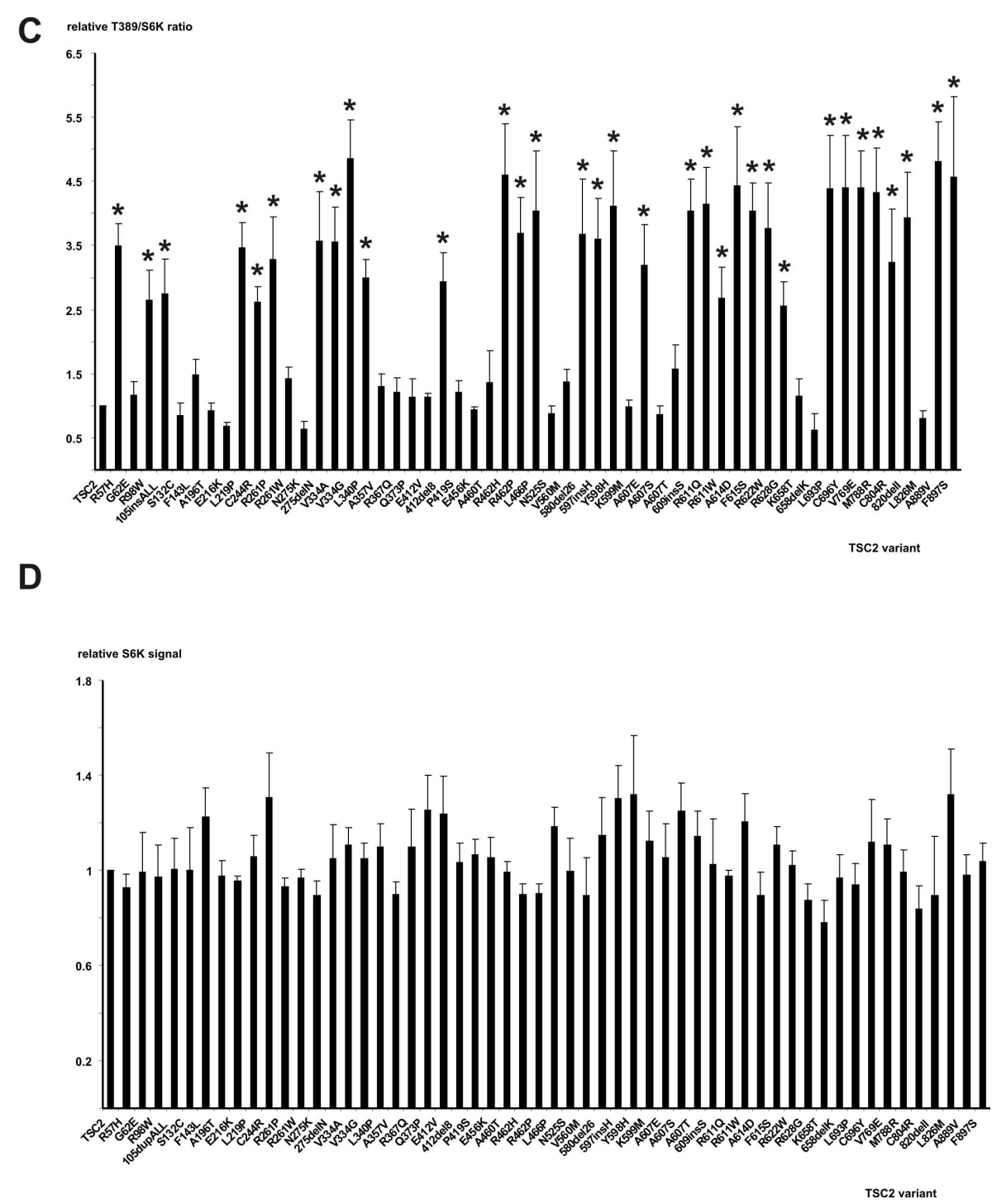

$175 \times 232 \mathrm{~mm}(300 \times 300$ DPI $)$

John Wiley \& Sons, Inc. 
Figure 4

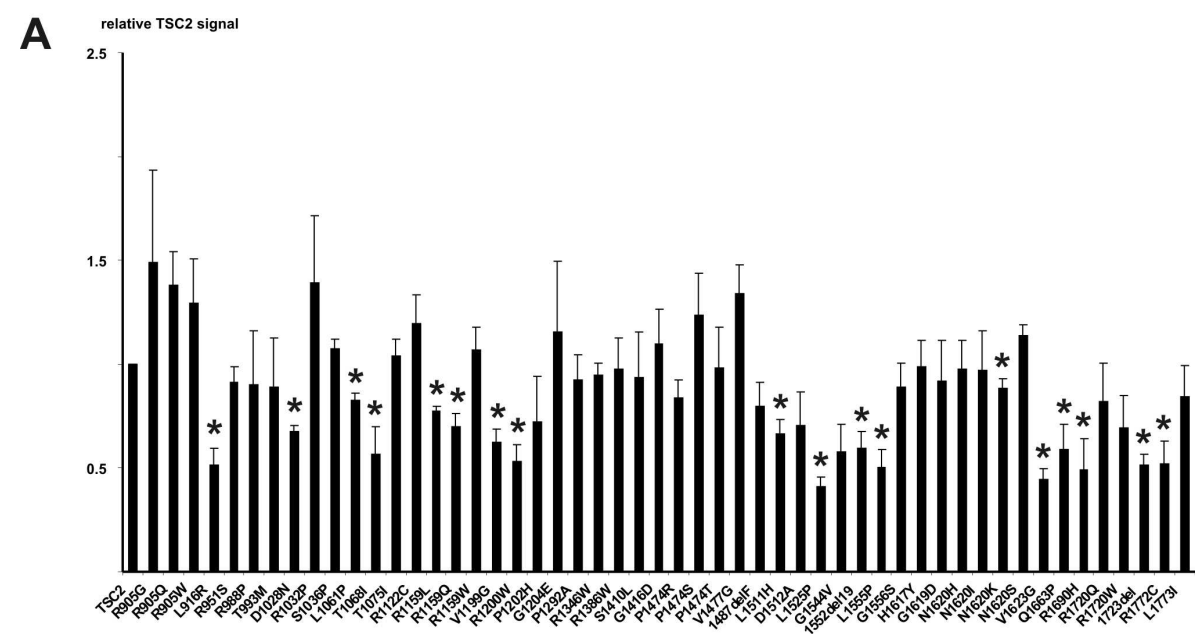

B

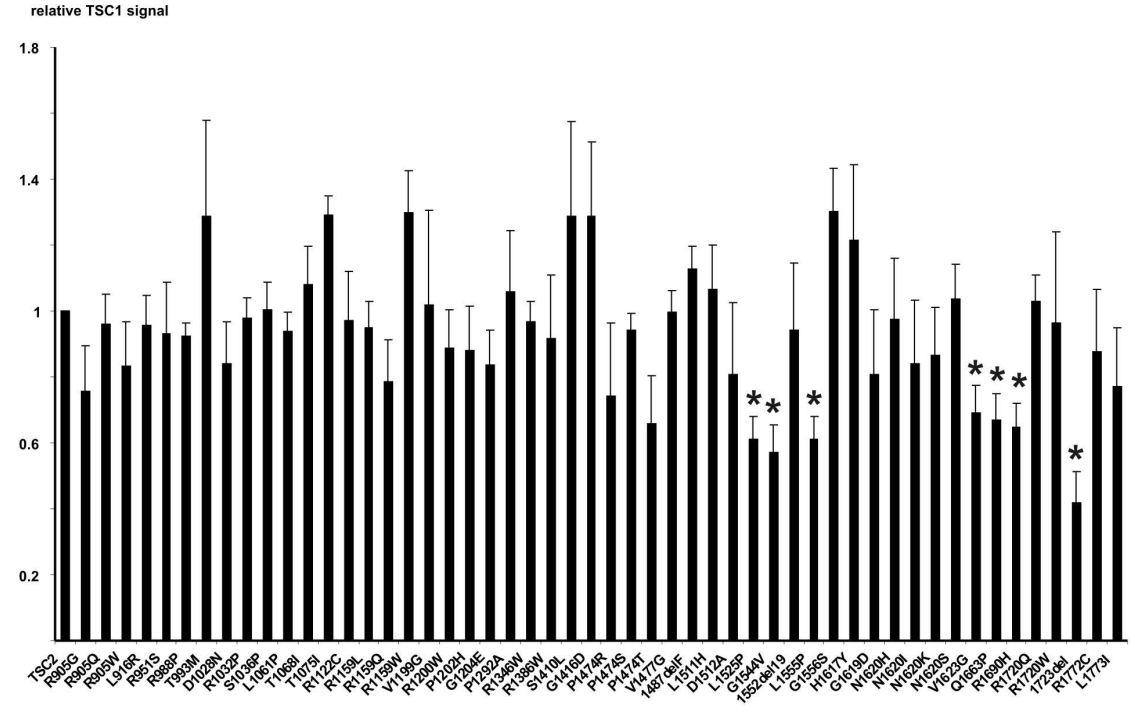

$171 \times 227 \mathrm{~mm}(300 \times 300$ DPI $)$

John Wiley \& Sons, Inc. 
Figure 4
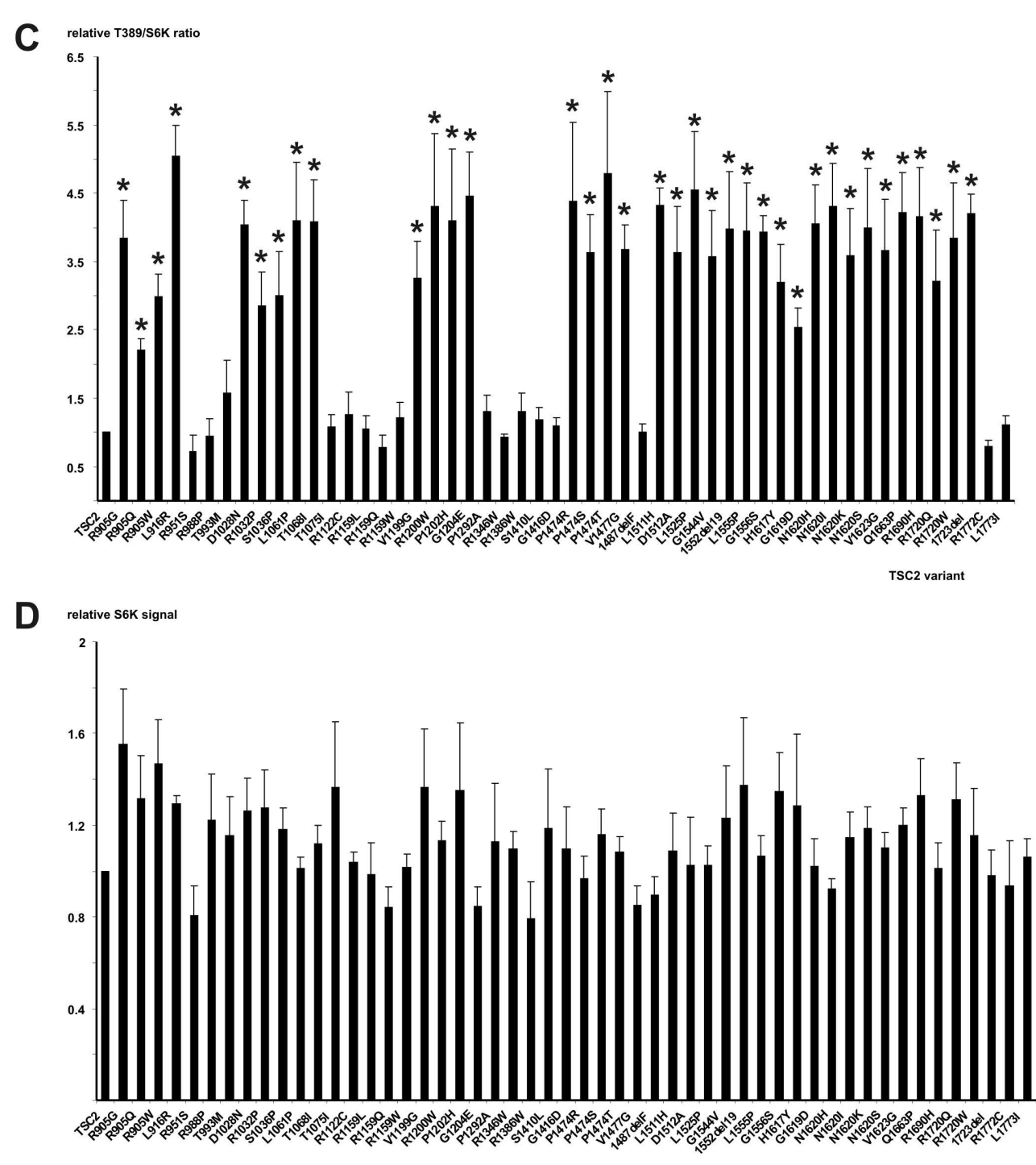

$174 \times 214 \mathrm{~mm}(300 \times 300$ DPI $)$

John Wiley \& Sons, Inc. 


\section{Supporting Figure S1:}

A

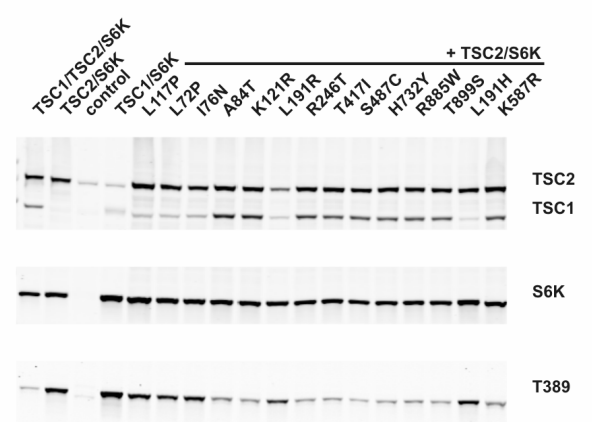

\section{C}

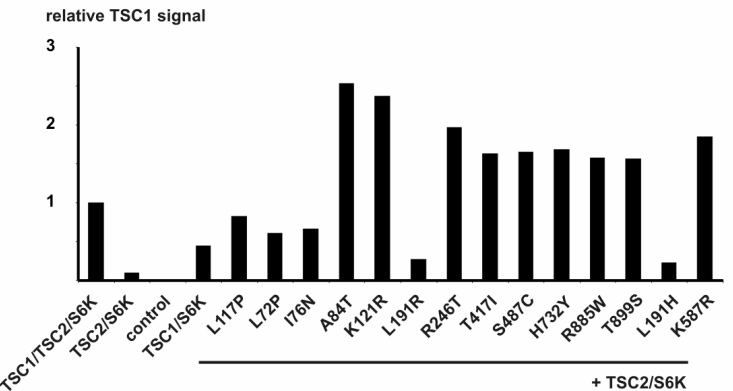

B

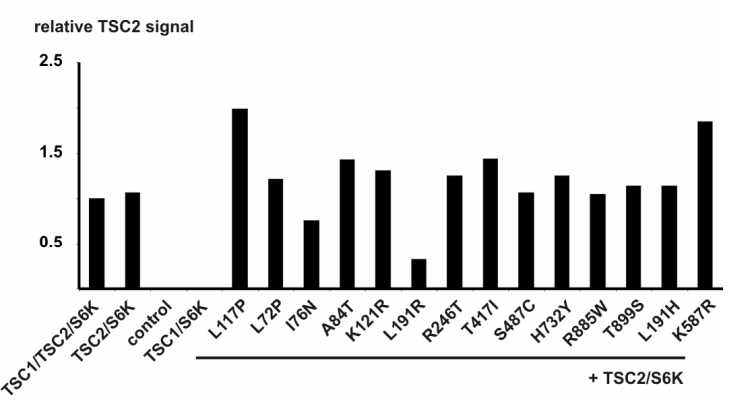

D

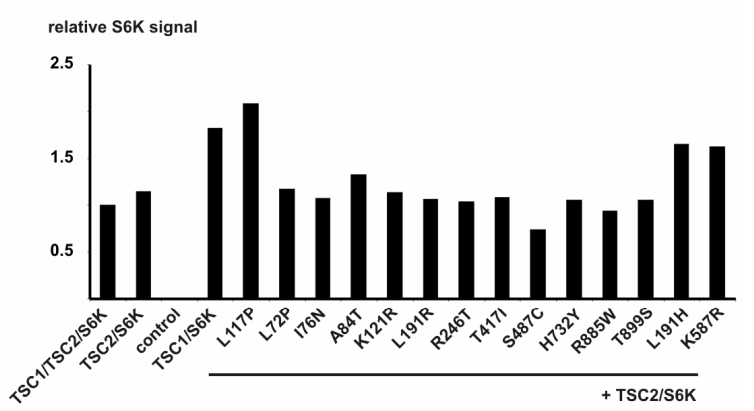

E

relative T389/S6K ratio

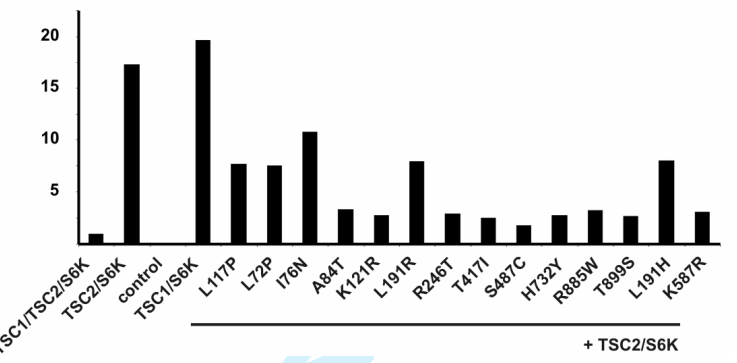

Immunoblot analysis of TSC1 variants. Cells were transfected with expression constructs encoding TSC2, S6K and wild-type TSC1 (TSC1/TSC2/S6K), TSC2, S6K and the pathogenic L117P variant (L117P), TSC2, S6K and the TSC1 variants, TSC2 and S6K only (TSC2/S6K), TSC1 and S6K only (TSC1/S6K) or with an empty vector (control) and analysed by immunoblotting.

(A) Immunoblot showing signals for wild-type TSC2 (TSC2), wild-type TSC1 and the TSC1 variants (TSC1), total S6K (S6K) and T389-phosphorylated S6K (T389). 
1 3 4 5 6 7

(B) Quantification of the TSC2 signals shown in (A), relative to the wild-type control (TSC1/TSC2/S6K).

(C) Quantification of the TSC1 signals shown in (A), relative to the wild-type control (TSC1/TSC2/S6K).

(D) Quantification of the total S6K signals shown in (A), relative to the wild-type control (TSC1/TSC2/S6K).

(E) Ratio of T389-phosphorylated S6K to total S6K in the presence of the TSC1 variants. The ratio of the signal for T389 phosphorylated S6K (T389) to the total S6K protein (S6K) was determined relative to the wild-type control (TSC1/TSC2/S6K; T389/S6K ratio $=1$ ) for each variant shown in $(\mathrm{A})$. 
Supporting Figure S2:

A

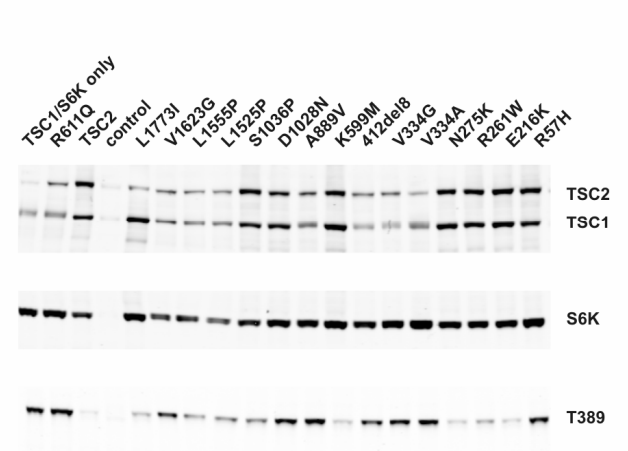

B
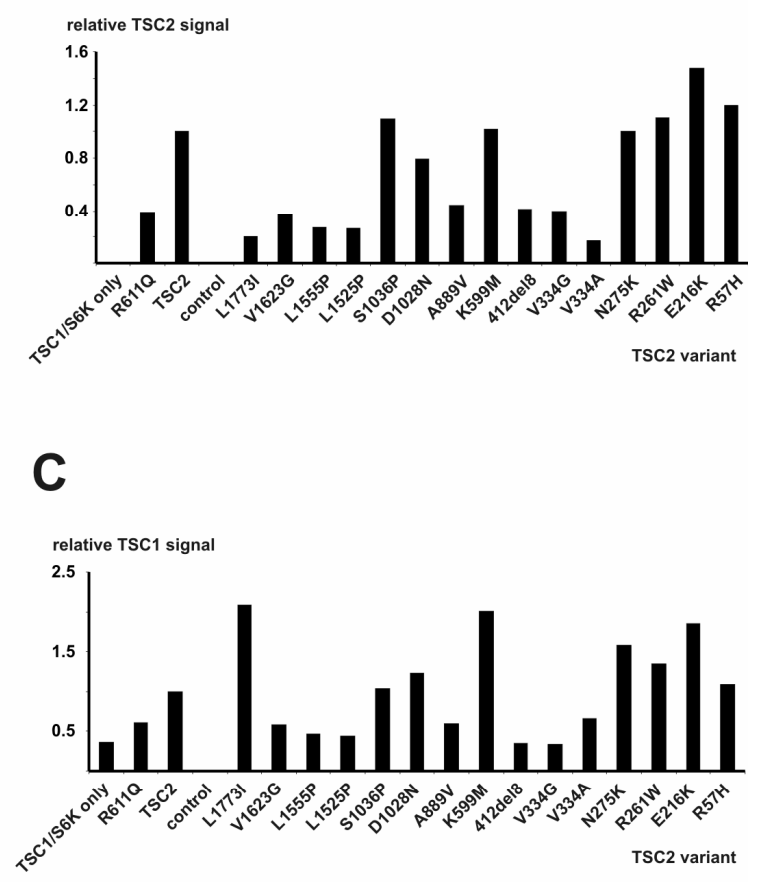

D

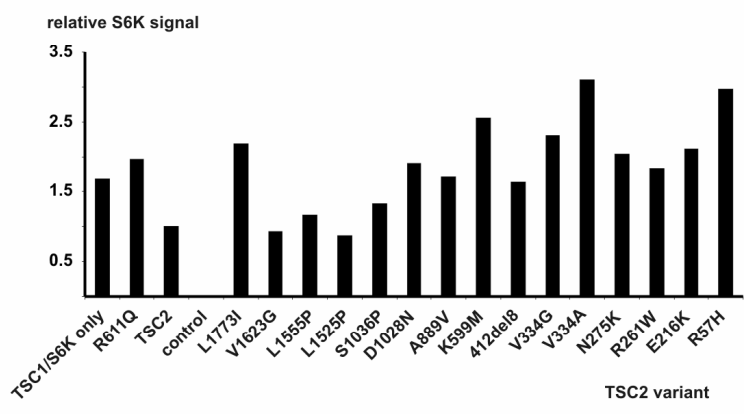

E

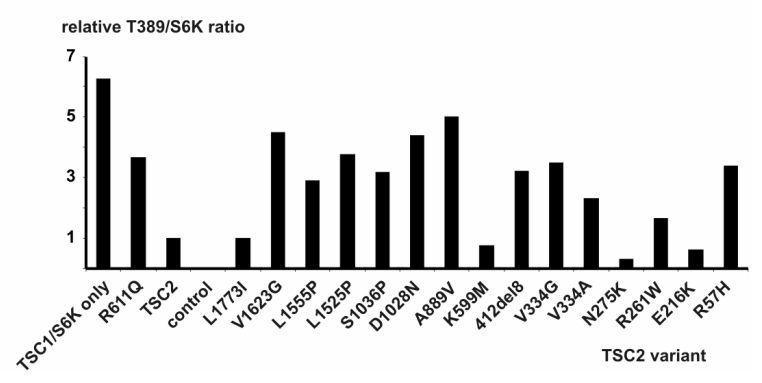


Immunoblot analysis of TSC2 variants. Cells were transfected with expression constructs encoding TSC1, S6K and wild-type TSC2 (TSC2), TSC1, S6K and the pathogenic R611Q variant (R611Q), TSC1, S6K and the TSC2 variants, or with an empty vector (control), and analysed by immunoblotting.

(A) Immunoblot showing signals for wild-type TSC2 and the TSC2 variants (TSC2), wild-type TSC1 (TSC1), total S6K (S6K) and T389-phosphorylated S6K (T389).

(B) Quantification of the TSC2 signals shown in (A), relative to the wild-type control (TSC2).

(C) Quantification of the TSC1 signals shown in (A), relative to the wild-type control (TSC2).

(D) Quantification of the total S6K signals shown in (A), relative to the wild-type control (TSC2).

(E) Ratio of T389-phosphorylated S6K to total S6K in the presence of the TSC2 variants. The ratio of the signal for T389 phosphorylated S6K (T389) to the total S6K protein (S6K) was determined relative to the wild-type control (TSC2; T389/S6K ratio =1) for each variant shown in $(\mathrm{A})$. 


\section{Supporting Figure S3:}

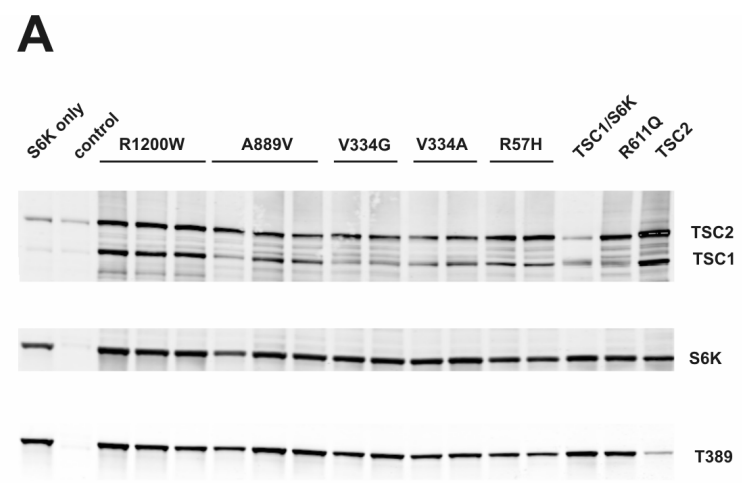

B

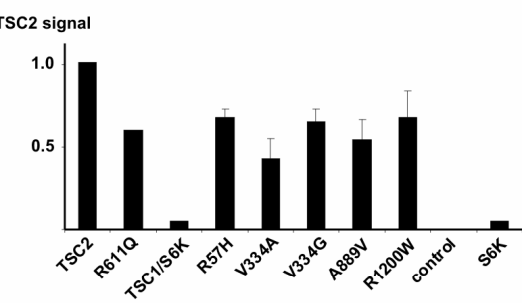

C

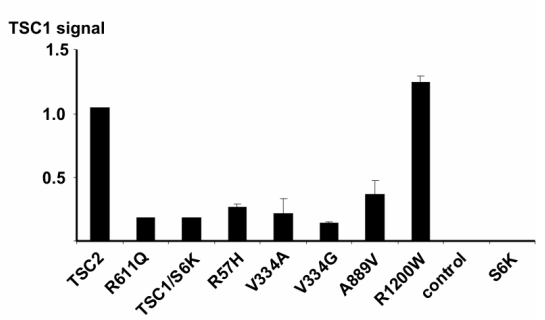

D

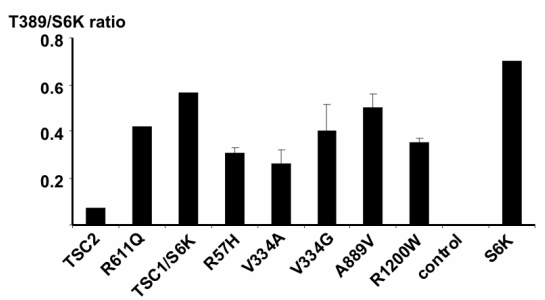

E

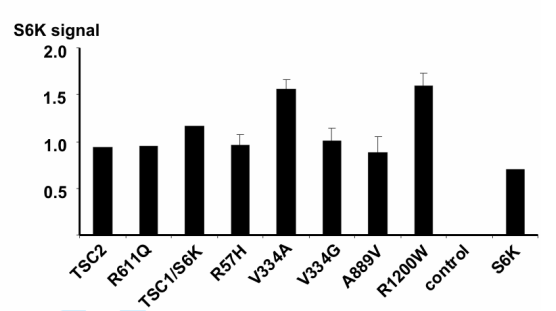

Immunoblot analysis of different DNA preparations of the TSC2 R1200W, A889V, V334G, V334A and R57H variants. Cells were transfected with expression constructs encoding TSC1, S6K and wild-type TSC2 (TSC2), TSC1, S6K and the pathogenic R611Q variant (R611Q), TSC1, S6K and the TSC2 variants, or with an empty vector (control), and analysed by immunoblotting. Three different preparations of the TSC2 R1200W and A889V variant expression constructs and 2 different preparations of the V334G, V334A and R57H variant constructs were tested. 
(A) Immunoblot showing signals for wild-type TSC2 and the TSC2 variants (TSC2), wild-type TSC1 (TSC1), total S6K (S6K) and T389-phosphorylated S6K (T389).

(B) Quantification of the TSC2 signals shown in (A). Mean signals for the different variants are shown relative to the wild-type control (TSC2). Error bars indicate the standard error of the mean.

(C) Quantification of the TSC1 signals shown in (A), relative to the wild-type control (TSC2).

(D) Quantification of the total S6K signals shown in (A), relative to the wild-type control (TSC2).

(E) Ratio of T389-phosphorylated S6K to total S6K in the presence of the TSC2 variants. The ratio of the signal for T389 phosphorylated S6K (T389) to the total S6K protein (S6K) was determined relative to the wild-type control (TSC2; T389/S6K ratio = 1) for each variant shown in $(\mathrm{A})$. 


\section{Supporting Figure S4:}

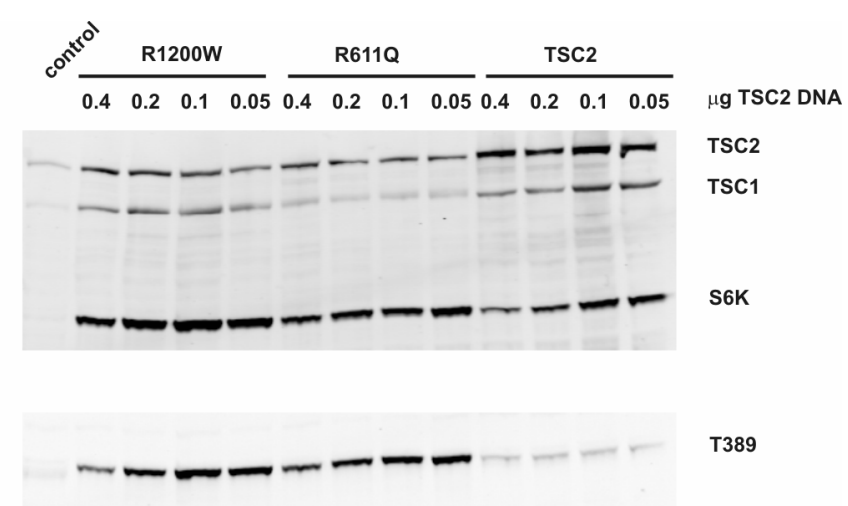

Immunoblot analysis of wild-type TSC2 and the TSC2 R1200W and R611Q variants.

Cells were transfected with expression constructs encoding TSC1 $(0.4 \mu \mathrm{g})$, S6K $(0.1 \mu \mathrm{g})$ and the indicated amounts of the TSC 2 expression constructs, and analysed by immunoblotting. Control cells (control) were transfected with $0.7 \mu \mathrm{g}$ empty vector. The effects of the TSC2 R1200W and R611Q variants on S6K T389 phosphorylation are clearly distinguishable from wild-type TSC2 across the whole range of transfected TSC2 expression construct DNA $(0.05-0.4 \mu \mathrm{g})$. 


\section{Supporting Figure S5:}

\section{TSC2 SIFT analysis}

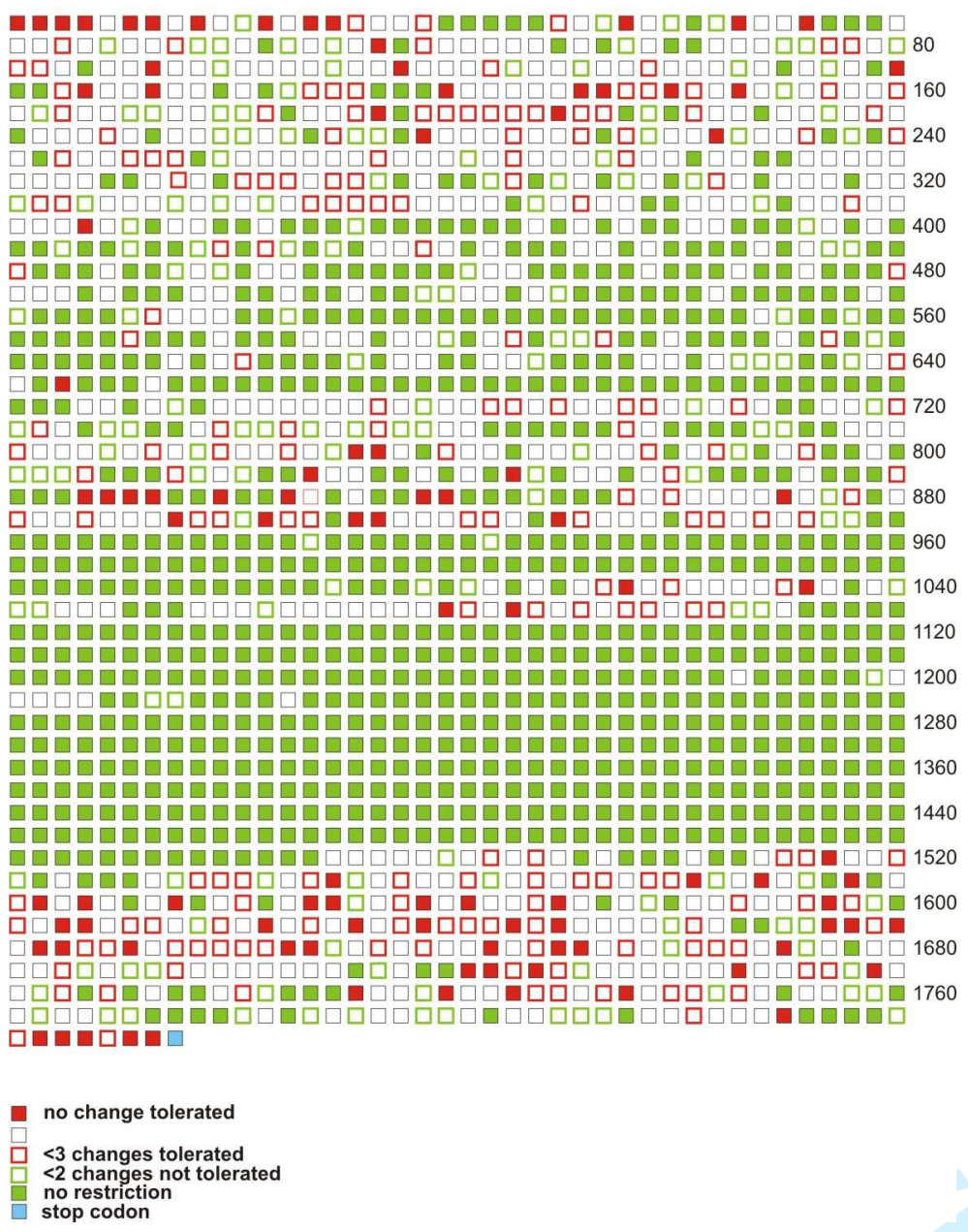

SIFT analysis of TSC2. The TSC2 amino acid sequence from the TSC2 LOVD was analysed using the SIFT algorithm. The number of tolerated and not tolerated substitutions was determined for each amino acid residue. In the figure each amino acid position is represented by a box. Solid green boxes represent positions that are completely tolerant (all substitutions possible, according to SIFT); open green boxes represent positions where 1 or 2 substitutions are not tolerated. Solid red boxes represent intolerant positions (no substitutions tolerated); open red boxes represent positions where 3 or fewer substitutions are tolerated. Empty boxes represent positions where between 3 and 17 substitutions are tolerated. 


\section{Supporting Figure S6:}

A

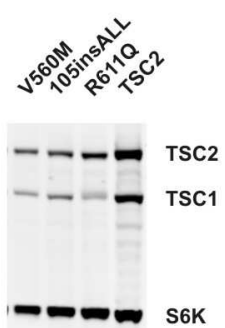

- - - T389
B

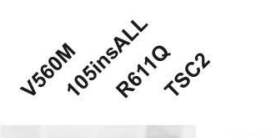

- - - $\mathrm{TSC2}$

$-\ldots-\mathrm{Tsc}_{1}$

$-56 \mathrm{~K}$

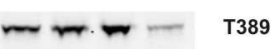

Immunoblot analysis of the TSC2 105insALL and V560M variants. Cells were transfected with expression constructs encoding TSC1, S6K and wild-type TSC2 (TSC2) or the TSC2 105insALL, V560M or R611Q variants, and analysed by immunoblotting in 2 separate experiments, as shown in A and B. Note the apparent increase in the T389-phosphorylated S6K signal for the V560M variant in B compared to $\mathrm{A}$. 


\section{Supporting Table S1:}

TSC1 variants. TSC1 nucleotide changes and exon numbers are given according to the TSC1 LOVD (http://www.lovd.nl/TSC1). Nucleotide numbering reflects the TSC1 cDNA numbering (Genbank AF013168.1; GI: 2331280) with +1 corresponding to the A of the ATG translation initiation codon in the reference sequence, according to journal guidelines (www.hgvs.org/mutnomen). Amino acid changes are numbered accordingly; the initiation codon is codon 1 . Nucleotide changes predicted to cause splicing defects are marked with an asterisk.

Amino acid substitutions predicted by SIFT to be tolerated (T) or not tolerated (NT) are indicated. Previously untested variants are indicated in bold. Links to the original references describing the different variants can be accessed via the TSC1 LOVD. Variants not previously listed in the TSC1 LOVD are indicated as 'not listed'.

\begin{tabular}{|l|l|l|l|l|}
\hline Exon & Variant & SIFT & LOVD & Functional \\
& $\begin{array}{l}\text { prediction } \\
\text { c.149T }>\text { C }\end{array}$ & NT & unknown & unstable, pathogenic \\
\hline 4 & $\begin{array}{l}\text { c.153A }>C \\
(p . E 51 D)\end{array}$ & T & probably no & probably neutral \\
\hline 4 & $\begin{array}{l}\text { c.182T }>C \\
(p . L 61 P)\end{array}$ & NT & probably & unstable, pathogenic \\
\hline 4 & c.215T $>$ C & NT & probably & unstable, \\
\hline 5 & $(\mathbf{p}$. L72P $)$ & pathogenic & pathogenic \\
\hline
\end{tabular}




\begin{tabular}{|c|c|c|c|c|}
\hline 5 & $\begin{array}{l}\text { c.227T }>A \\
(\text { p.I76N) }\end{array}$ & NT & unknown & $\begin{array}{l}\text { unstable, } \\
\text { pathogenic }\end{array}$ \\
\hline 5 & $\begin{array}{l}\text { c.245A }>C \\
(p . K 82 T)\end{array}$ & $\mathbf{T}$ & unknown & probably neutral \\
\hline 5 & $\begin{array}{l}\text { c.250G>A } \\
(\text { p.A84T) }\end{array}$ & $\mathbf{T}$ & $\begin{array}{l}\text { probably no } \\
\text { pathogenicity }\end{array}$ & probably neutral \\
\hline 5 & $\begin{array}{l}\text { c.278T>G } \\
\text { (p.L93R) }\end{array}$ & NT & $\begin{array}{l}\text { probably } \\
\text { pathogenic }\end{array}$ & $\begin{array}{l}\text { unstable, } \\
\text { destabilising, } \\
\text { pathogenic }\end{array}$ \\
\hline 5 & $\begin{array}{l}\text { c.346T }>G \\
(\text { p.L116V) }\end{array}$ & $\mathbf{T}$ & not listed & probably neutral \\
\hline 5 & $\begin{array}{l}\text { c.350T>C } \\
(p . L 117 P)\end{array}$ & NT & $\begin{array}{l}\text { probably } \\
\text { pathogenic }\end{array}$ & unstable, pathogenic \\
\hline 5 & $\begin{array}{l}\text { c.362A>G* } \\
(\text { p.K121R) }\end{array}$ & $\mathbf{T}$ & unknown & $\begin{array}{l}\text { probably neutral } \\
\text { (predicted splice } \\
\text { mutation) }\end{array}$ \\
\hline 6 & $\begin{array}{l}\text { c.381_383delTGT** } \\
\text { (p.128delV) }\end{array}$ & - & unknown & unstable, pathogenic \\
\hline 6 & $\begin{array}{l}\text { c.397G>T } \\
\text { (p.V133F) }\end{array}$ & NT & unknown & unstable, pathogenic \\
\hline 7 & $\begin{array}{l}\text { c.539T }>C \\
\text { (p.L180P) }\end{array}$ & NT & $\begin{array}{l}\text { probably } \\
\text { pathogenic }\end{array}$ & unstable, pathogenic \\
\hline 7 & $\begin{array}{l}\text { c. } 568 \mathrm{C}>\mathrm{T} \\
(\mathrm{p} . \mathrm{R} 190 \mathrm{C})\end{array}$ & NT & $\begin{array}{l}\text { no known } \\
\text { pathogenicity }\end{array}$ & probably neutral \\
\hline 7 & c.569G $>C$ & NT & unknown & unstable, pathogenic \\
\hline
\end{tabular}




\begin{tabular}{|c|c|c|c|c|}
\hline & (p.R190P) & & & \\
\hline 7 & $\begin{array}{l}\text { c.572T>A } \\
\text { (p.L191H) }\end{array}$ & NT & $\begin{array}{l}\text { probably } \\
\text { pathogenic }\end{array}$ & unstable, pathogenic \\
\hline 7 & $\begin{array}{l}\text { c.572T }>G \\
(p . L 191 R)\end{array}$ & NT & unknown & $\begin{array}{l}\text { unstable, } \\
\text { pathogenic }\end{array}$ \\
\hline 7 & $\begin{array}{l}\text { c.593_595delACT } \\
\text { (p.N198F199delinsI) }\end{array}$ & - & $\begin{array}{l}\text { probably } \\
\text { pathogenic }\end{array}$ & $\begin{array}{l}\text { unstable, } \\
\text { destabilising, } \\
\text { pathogenic }\end{array}$ \\
\hline 7 & $\begin{array}{l}\text { c.602_604delCCT } \\
\text { (p.S201del) }\end{array}$ & - & unknown & $\begin{array}{l}\text { unstable, } \\
\text { pathogenic }\end{array}$ \\
\hline 7 & $\begin{array}{l}\text { c.647T >C } \\
(p . F 216 S)\end{array}$ & NT & $\begin{array}{l}\text { probably no } \\
\text { pathogenicity; } \\
\text { updated to } \\
\text { unknown }\end{array}$ & $\begin{array}{l}\text { unstable, } \\
\text { pathogenic }\end{array}$ \\
\hline 8 & $\begin{array}{l}\text { c.671T }>\mathrm{G} \\
\text { (p.M224R) }\end{array}$ & NT & $\begin{array}{l}\text { probably } \\
\text { pathogenic }\end{array}$ & $\begin{array}{l}\text { unstable, } \\
\text { destabilising, } \\
\text { pathogenic }\end{array}$ \\
\hline 8 & $\begin{array}{l}\text { c. } 737 \mathrm{G}>\mathrm{A}^{*} \\
\text { (p.R246K) }\end{array}$ & NT & $\begin{array}{l}\text { probably } \\
\text { pathogenic }\end{array}$ & $\begin{array}{l}\text { probably neutral } \\
\text { (predicted splice } \\
\text { mutation) }\end{array}$ \\
\hline 8 & $\begin{array}{l}\text { c.737G }>\text { C* } \\
(\text { p.R246T) }\end{array}$ & NT & $\begin{array}{l}\text { probably } \\
\text { pathogenic }\end{array}$ & $\begin{array}{l}\text { probably neutral } \\
\text { (predicted splice } \\
\text { mutation) }\end{array}$ \\
\hline 9 & $\begin{array}{l}\text { c.853T }>\text { G } \\
(\text { p.F285V) }\end{array}$ & $\mathbf{T}$ & not listed & probably neutral \\
\hline
\end{tabular}




\begin{tabular}{|c|c|c|c|c|}
\hline 9 & $\begin{array}{l}\text { c.913G }>A^{*} \\
\text { (p.G305R) }\end{array}$ & $\mathrm{T}$ & $\begin{array}{l}\text { probably } \\
\text { pathogenic }\end{array}$ & $\begin{array}{l}\text { probably neutral } \\
\text { (predicted splice } \\
\text { mutation) }\end{array}$ \\
\hline 9 & $\begin{array}{l}\text { c. } 913 \mathrm{G}>\mathrm{T}^{*} \\
\text { p.G305W }\end{array}$ & $\mathrm{T}$ & $\begin{array}{l}\text { probably } \\
\text { pathogenic }\end{array}$ & $\begin{array}{l}\text { probably neutral } \\
\text { (predicted splice } \\
\text { mutation) }\end{array}$ \\
\hline 10 & $\begin{array}{l}\text { c. } 1001 \mathrm{C}>\mathrm{T} \\
\text { p.S334L }\end{array}$ & $\mathrm{T}$ & $\begin{array}{l}\text { probably no } \\
\text { pathogenicity }\end{array}$ & probably neutral \\
\hline 12 & $\begin{array}{l}\text { c.1250C }>T \\
(p . T 417 I)\end{array}$ & $\mathbf{T}$ & $\begin{array}{l}\text { no known } \\
\text { pathogenicity }\end{array}$ & probably neutral \\
\hline 14 & $\begin{array}{l}\text { c. } 1433 \mathrm{~A}>\mathrm{G}^{*} \\
\text { (p.E478G) }\end{array}$ & $\mathrm{T}$ & unknown & probably neutral \\
\hline 14 & $\begin{array}{l}\text { c.1433A }>\mathrm{G}^{*} \\
\text { (p.E478GinsGN) }\end{array}$ & - & unknown & probably neutral \\
\hline 15 & $\begin{array}{l}\text { c.1460C>G } \\
\text { (p.S487C) }\end{array}$ & $\mathbf{T}$ & not listed & probably neutral \\
\hline 15 & $\begin{array}{l}\text { c.1526G >A } \\
\text { (p.R509Q) }\end{array}$ & $\mathrm{T}$ & $\begin{array}{l}\text { probably no } \\
\text { pathogenicity }\end{array}$ & probably neutral \\
\hline 15 & $\begin{array}{l}\text { c. } 1648 C>G \\
\text { (p.Q550E) }\end{array}$ & $\mathrm{T}$ & unknown & probably neutral \\
\hline 15 & $\begin{array}{l}\text { c.1760A>G } \\
(\text { p.K587R) }\end{array}$ & $\mathbf{T}$ & $\begin{array}{l}\text { no known } \\
\text { pathogenicity }\end{array}$ & probably neutral \\
\hline 15 & $\begin{array}{l}\text { c.1849C>G } \\
\text { (p.H617D) }\end{array}$ & $\mathbf{T}$ & not listed & probably neutral \\
\hline 15 & c. $1974 C>G$ & $\mathrm{~T}$ & probably no & probably neutral \\
\hline
\end{tabular}




\begin{tabular}{|c|c|c|c|c|}
\hline & (p.D658E) & & pathogenicity & \\
\hline 15 & $\begin{array}{l}\text { c. } 1976 \mathrm{C}>\mathrm{T} \\
\text { (p.A659V) }\end{array}$ & $\mathrm{T}$ & $\begin{array}{l}\text { probably no } \\
\text { pathogenicity }\end{array}$ & probably neutral \\
\hline 17 & $\begin{array}{l}\text { c.2194C>T } \\
\text { (p.H732Y) }\end{array}$ & NT & $\begin{array}{l}\text { no known } \\
\text { pathogenicity }\end{array}$ & probably neutral \\
\hline 19 & $\begin{array}{l}\text { c. } 2420 \mathrm{~T}>\mathrm{C} \\
(\mathrm{p} . \mathrm{I} 807 \mathrm{~T})\end{array}$ & $\mathrm{T}$ & unknown & probably neutral \\
\hline 21 & $\begin{array}{l}\text { c.2653C>T } \\
(\text { p.R885W) }\end{array}$ & $\mathbf{T}$ & unknown & probably neutral \\
\hline 21 & $\begin{array}{l}\text { c.2696C>G } \\
\text { (p.T899S) }\end{array}$ & $\mathbf{T}$ & unknown & probably neutral \\
\hline 23 & $\begin{array}{l}\text { c. } 3103 \mathrm{G}>\mathrm{A} \\
\text { (p.G1035S) }\end{array}$ & $\mathrm{T}$ & $\begin{array}{l}\text { no known } \\
\text { pathogenicity }\end{array}$ & probably neutral \\
\hline 23 & $\begin{array}{l}\text { c.3184C }>T \\
(p . R 1062 W)\end{array}$ & $\mathbf{T}$ & unknown & probably neutral \\
\hline 23 & $\begin{array}{l}\text { c.3290G }>A \\
\text { (p.R1097H) }\end{array}$ & NT & $\begin{array}{l}\text { probably no } \\
\text { pathogenicity }\end{array}$ & probably neutral \\
\hline
\end{tabular}




\section{Supporting Table S2:}

TSC2 variants (amino acids 1 - 900). TSC2 nucleotide changes and exon numbers are given according to the TSC2 LOVD (http://www.lovd.nl/TSC2). Nucleotide numbering reflects the TSC2 cDNA numbering (Genbank X75621; GI:450351) with +1

corresponding to the A of the ATG translation initiation codon in the reference sequence, according to journal guidelines (www.hgvs.org/mutnomen). Amino acid changes were numbered accordingly; the initiation codon is codon 1 . Nucleotide changes predicted to cause splicing defects are marked with an asterisk.

Amino acid substitutions predicted by SIFT to be tolerated (T) or not tolerated (NT) are indicated. Links to the original references describing the different variants can be accessed via the TSC2 LOVD. Variants not previously listed in the TSC2 LOVD are indicated as 'not listed'. Previously untested variants are indicated in bold.

\begin{tabular}{|c|c|c|c|c|}
\hline Exon & Variant & $\begin{array}{l}\text { SIFT } \\
\text { prediction }\end{array}$ & $\begin{array}{l}\text { LOVD } \\
\text { classification }\end{array}$ & $\begin{array}{l}\text { Functional } \\
\text { assessment }\end{array}$ \\
\hline 2 & $\begin{array}{l}\text { c.170G >A } \\
(\text { p.R57H) }\end{array}$ & NT & not listed & $\begin{array}{l}\text { unstable, } \\
\text { pathogenic }\end{array}$ \\
\hline 2 & $\begin{array}{l}\text { c. } 185 \mathrm{G}>\mathrm{A} \\
\text { (p.G62E) }\end{array}$ & $\mathrm{T}$ & unknown & probably neutral \\
\hline 3 & $\begin{array}{l}\text { c. } 292 \mathrm{C}>\mathrm{T} \\
(\mathrm{p} . \mathrm{R} 98 \mathrm{~W})\end{array}$ & NT & unknown & $\begin{array}{l}\text { destabilising, } \\
\text { pathogenic }\end{array}$ \\
\hline 3 & $\begin{array}{l}\text { c.307_315dup } \\
\text { (p.105insALL) }\end{array}$ & - & unknown & $\begin{array}{l}\text { destabilising, } \\
\text { pathogenic }\end{array}$ \\
\hline 4 & $\begin{array}{l}\text { c.395C>G } \\
\text { (p.S132C) }\end{array}$ & $\mathrm{T}$ & $\begin{array}{l}\text { probably no } \\
\text { pathogenicity }\end{array}$ & probably neutral \\
\hline
\end{tabular}




\begin{tabular}{|c|c|c|c|c|}
\hline 4 & $\begin{array}{l}\text { c. } 447 \mathrm{C}>\mathrm{G} \\
\text { (p.F143L) }\end{array}$ & $\mathrm{T}$ & $\begin{array}{l}\text { probably no } \\
\text { pathogenicity }\end{array}$ & probably neutral \\
\hline 5 & $\begin{array}{l}c .586 G>A \\
\text { (p.A196T) }\end{array}$ & $\mathrm{T}$ & $\begin{array}{l}\text { probably no } \\
\text { pathogenicity }\end{array}$ & probably neutral \\
\hline 6 & $\begin{array}{l}c .646 G>A \\
(p . E 216 K)\end{array}$ & $\mathbf{T}$ & not listed & probably neutral \\
\hline 7 & $\begin{array}{l}\text { c.656T >C } \\
(\text { p.L219P) }\end{array}$ & NT & not listed & $\begin{array}{l}\text { destabilising, } \\
\text { pathogenic }\end{array}$ \\
\hline 7 & $\begin{array}{l}\text { c.730T>C } \\
\text { (p.C244R) }\end{array}$ & NT & $\begin{array}{l}\text { probably } \\
\text { pathogenic }\end{array}$ & $\begin{array}{l}\text { unstable, } \\
\text { destabilising, } \\
\text { pathogenic }\end{array}$ \\
\hline 8 & $\begin{array}{l}\text { c.782G>C } \\
(\text { p.R261P) }\end{array}$ & $\mathbf{T}$ & $\begin{array}{l}\text { probably } \\
\text { pathogenic }\end{array}$ & $\begin{array}{l}\text { destabilising, } \\
\text { pathogenic }\end{array}$ \\
\hline 8 & $\begin{array}{l}\text { c.781C>T } \\
(\text { p.R261W) }\end{array}$ & NT & $\begin{array}{l}\text { probably no } \\
\text { pathogenicity }\end{array}$ & probably neutral \\
\hline 8 & $\begin{array}{l}\text { c.825C>G } \\
(\text { p.N275K) }\end{array}$ & $\mathbf{T}$ & not listed & probably neutral \\
\hline 8 & $\begin{array}{l}\text { c.824_826del } \\
\text { (p.275delN) }\end{array}$ & - & unknown & $\begin{array}{l}\text { destabilising, } \\
\text { pathogenic }\end{array}$ \\
\hline 10 & $\begin{array}{l}\text { c.1001T>C } \\
(\text { p.V334A) }\end{array}$ & NT & not listed & $\begin{array}{l}\text { unstable, } \\
\text { destabilising, } \\
\text { pathogenic }\end{array}$ \\
\hline 10 & $\begin{array}{l}\text { c.1001T>G } \\
(\text { p.V334G) }\end{array}$ & NT & $\begin{array}{l}\text { probably } \\
\text { pathogenic }\end{array}$ & $\begin{array}{l}\text { unstable, } \\
\text { destabilising, } \\
\text { pathogenic }\end{array}$ \\
\hline
\end{tabular}




\begin{tabular}{|c|c|c|c|c|}
\hline 10 & $\begin{array}{l}\text { c.1019T>C } \\
\text { (p.L340P) }\end{array}$ & NT & not listed & pathogenic \\
\hline 10 & $\begin{array}{l}\text { c.1070C>T } \\
\text { (p.A357V) }\end{array}$ & $\mathbf{T}$ & not listed & probably neutral \\
\hline 10 & $\begin{array}{l}\text { c.1100G >A } \\
\text { (p.R367Q) }\end{array}$ & $\mathrm{T}$ & $\begin{array}{l}\text { no known } \\
\text { pathogenicity }\end{array}$ & probably neutral \\
\hline 10 & $\begin{array}{l}\text { c.1118A>C* } \\
\text { (p.Q373P) }\end{array}$ & $\mathrm{T}$ & unknown & $\begin{array}{l}\text { probably neutral } \\
\text { (predicted splice } \\
\text { mutation) }\end{array}$ \\
\hline 11 & $\begin{array}{l}\text { c. } 1235 \mathrm{~A}>\mathrm{T}^{*} \\
\text { (p.E412V) }\end{array}$ & NT & unknown & $\begin{array}{l}\text { probably neutral } \\
\text { (splice mutation) }\end{array}$ \\
\hline 11 & $\begin{array}{l}\text { c. } 1235 \mathrm{~A}>\mathrm{T}^{*} \\
\text { (p.412del } 8)\end{array}$ & - & unknown & $\begin{array}{l}\text { unstable, } \\
\text { destabilising, } \\
\text { pathogenic }\end{array}$ \\
\hline 11 & $\begin{array}{l}\text { c.1255C>T* } \\
\text { (p.P419S) }\end{array}$ & NT & $\begin{array}{l}\text { probably } \\
\text { pathogenic }\end{array}$ & $\begin{array}{l}\text { probably neutral } \\
\text { (predicted splice } \\
\text { mutation) }\end{array}$ \\
\hline 13 & $\begin{array}{l}\text { c.1366A>G } \\
\text { (p.E456K) }\end{array}$ & $\mathbf{T}$ & not listed & probably neutral \\
\hline 13 & $\begin{array}{l}\text { c.1378G >A } \\
\text { (p.A460T) }\end{array}$ & $\mathbf{T}$ & unknown & probably neutral \\
\hline 13 & $\begin{array}{l}\text { c.1385G >A } \\
\text { (p.R462H) }\end{array}$ & NT & not listed & $\begin{array}{l}\text { unstable, } \\
\text { destabilising, } \\
\text { pathogenic }\end{array}$ \\
\hline 13 & c.1385_1386del & NT & not listed & unstable, \\
\hline
\end{tabular}




\begin{tabular}{|c|c|c|c|c|}
\hline & $\begin{array}{l}\text { insCT } \\
(p . R 462 P)\end{array}$ & & & $\begin{array}{l}\text { destabilising, } \\
\text { pathogenic }\end{array}$ \\
\hline 13 & $\begin{array}{l}\text { c.1397T>C } \\
\text { (p.L466P) }\end{array}$ & $\mathbf{T}$ & unknown & $\begin{array}{l}\text { unstable, } \\
\text { destabilising, } \\
\text { pathogenic }\end{array}$ \\
\hline 14 & $\begin{array}{l}\text { c.1574A>G } \\
\text { (p.N525S) }\end{array}$ & $\mathrm{T}$ & $\begin{array}{l}\text { no known } \\
\text { pathogenicity }\end{array}$ & probably neutral \\
\hline 15 & $\begin{array}{l}\text { c.1678G >A } \\
(\text { p.V560M) }\end{array}$ & $\mathbf{T}$ & not listed & pathogenic \\
\hline 16 & $\begin{array}{l}\text { c.1736del78 } \\
\text { (p.580del26) }\end{array}$ & - & unknown & $\begin{array}{l}\text { unstable, } \\
\text { destabilising, } \\
\text { pathogenic }\end{array}$ \\
\hline 16 & $\begin{array}{l}\text { c.1790insCAC } \\
\text { (p.597insH) }\end{array}$ & - & unknown & $\begin{array}{l}\text { destabilising, } \\
\text { pathogenic }\end{array}$ \\
\hline 16 & $\begin{array}{l}\text { c. } 1792 \mathrm{~T}>\mathrm{C} \\
\text { (p.Y598H) }\end{array}$ & $\mathrm{T}$ & $\begin{array}{l}\text { probably } \\
\text { pathogenic }\end{array}$ & $\begin{array}{l}\text { destabilising, } \\
\text { pathogenic }\end{array}$ \\
\hline 16 & $\begin{array}{l}\text { c. } 1796 \mathrm{~A}>\mathrm{T} \\
\text { (p.K599M) }\end{array}$ & $\mathrm{T}$ & $\begin{array}{l}\text { pathogenic; } \\
\text { updated to } \\
\text { unknown }\end{array}$ & probably neutral \\
\hline 16 & $\begin{array}{l}\text { c. } 1820 \mathrm{C}>\mathrm{A} \\
\text { (p.A607E) }\end{array}$ & $\mathrm{T}$ & unknown & $\begin{array}{l}\text { unstable, } \\
\text { destabilising, } \\
\text { pathogenic }\end{array}$ \\
\hline 16 & $\begin{array}{l}\text { c.1819G }>\text { T } \\
\text { (p.A607S) }\end{array}$ & $\mathbf{T}$ & not listed & probably neutral \\
\hline 16 & c.1819G $>A$ & $\mathbf{T}$ & probably no & probably neutral \\
\hline
\end{tabular}




\begin{tabular}{|c|c|c|c|c|}
\hline & (p.A607T) & & pathogenicity & \\
\hline 16 & $\begin{array}{l}\text { c.1826_1828du } \\
\mathrm{p} \\
\text { (p.609insS) }\end{array}$ & - & pathogenic & $\begin{array}{l}\text { destabilising, } \\
\text { pathogenic }\end{array}$ \\
\hline 16 & $\begin{array}{l}\text { c.1832G }>A \\
\text { (p.R611Q) }\end{array}$ & NT & pathogenic & $\begin{array}{l}\text { unstable, } \\
\text { destabilising, } \\
\text { pathogenic }\end{array}$ \\
\hline 16 & $\begin{array}{l}\text { c. } 1831 \mathrm{C}>\mathrm{T} \\
\text { (p.R611W) }\end{array}$ & NT & pathogenic & $\begin{array}{l}\text { destabilising, } \\
\text { pathogenic }\end{array}$ \\
\hline 17 & $\begin{array}{l}\text { c. } 1841 C>A^{*} \\
\text { (p.A614D) }\end{array}$ & $\mathrm{T}$ & $\begin{array}{l}\text { probably } \\
\text { pathogenic }\end{array}$ & $\begin{array}{l}\text { unstable, } \\
\text { destabilising, } \\
\text { pathogenic }\end{array}$ \\
\hline 17 & $\begin{array}{l}\text { c. } 1844 \mathrm{~T}>\mathrm{C} \\
\text { (p.F615S) }\end{array}$ & $\mathrm{T}$ & $\begin{array}{l}\text { no known } \\
\text { pathogenicity; } \\
\text { updated to } \\
\text { unknown }\end{array}$ & $\begin{array}{l}\text { destabilising, } \\
\text { pathogenic }\end{array}$ \\
\hline 17 & $\begin{array}{l}\text { c.1864C>T } \\
\text { (p.R622W) }\end{array}$ & NT & unknown & $\begin{array}{l}\text { unstable, } \\
\text { destabilising, } \\
\text { pathogenic }\end{array}$ \\
\hline 17 & $\begin{array}{l}\text { c.1882C>G* } \\
\text { (p.R628G) }\end{array}$ & $\mathbf{T}$ & unknown & pathogenic \\
\hline 18 & $\begin{array}{l}\text { c.1973A>C } \\
\text { (p.K658T) }\end{array}$ & $\mathbf{T}$ & not listed & probably neutral \\
\hline 18 & $\begin{array}{l}\text { c.1972_1974del } \\
\text { (p.658delK) }\end{array}$ & - & $\begin{array}{l}\text { no known } \\
\text { pathogenicity }\end{array}$ & probably neutral \\
\hline
\end{tabular}




\begin{tabular}{|c|c|c|c|c|}
\hline 18 & $\begin{array}{l}\text { c.2078T >C } \\
\text { (p.L693P) }\end{array}$ & NT & $\begin{array}{l}\text { probably } \\
\text { pathogenic }\end{array}$ & $\begin{array}{l}\text { unstable, } \\
\text { destabilising, } \\
\text { pathogenic }\end{array}$ \\
\hline 18 & $\begin{array}{l}\text { c. } 2087 \mathrm{G}>\mathrm{A} \\
\text { (p.C696Y) }\end{array}$ & NT & unknown & $\begin{array}{l}\text { unstable, } \\
\text { destabilising, } \\
\text { pathogenic }\end{array}$ \\
\hline 20 & $\begin{array}{l}\text { c. } 2306 \mathrm{~T}>\mathrm{A} \\
\text { (p.V769E) }\end{array}$ & $\mathrm{T}$ & $\begin{array}{l}\text { probably } \\
\text { pathogenic }\end{array}$ & $\begin{array}{l}\text { unstable, } \\
\text { destabilising, } \\
\text { pathogenic }\end{array}$ \\
\hline 21 & $\begin{array}{l}\text { c.2363T>G } \\
\text { (p.M788R) }\end{array}$ & NT & $\begin{array}{l}\text { probably } \\
\text { pathogenic }\end{array}$ & $\begin{array}{l}\text { unstable, } \\
\text { destabilising, } \\
\text { pathogenic }\end{array}$ \\
\hline 21 & $\begin{array}{l}\text { c.2410T>C } \\
\text { (p.C804R) }\end{array}$ & NT & $\begin{array}{l}\text { probably } \\
\text { pathogenic }\end{array}$ & $\begin{array}{l}\text { destabilising, } \\
\text { pathogenic }\end{array}$ \\
\hline 21 & $\begin{array}{l}\text { c.2458_2460del } \\
\text { (p.820delI) }\end{array}$ & - & pathogenic & $\begin{array}{l}\text { unstable, } \\
\text { destabilising, } \\
\text { pathogenic }\end{array}$ \\
\hline 21 & $\begin{array}{l}\text { c. } 2476 C>A \\
\text { (p.L826M) }\end{array}$ & NT & $\begin{array}{l}\text { no known } \\
\text { pathogenicity }\end{array}$ & probably neutral \\
\hline 23 & $\begin{array}{l}\text { c.2666C>T } \\
(\text { p.A889V) }\end{array}$ & NT & $\begin{array}{l}\text { probably } \\
\text { pathogenic }\end{array}$ & $\begin{array}{l}\text { unstable, } \\
\text { destabilising, } \\
\text { pathogenic }\end{array}$ \\
\hline 23 & $\begin{array}{l}\text { c.2690T >C } \\
(\text { p.F897S })\end{array}$ & NT & $\begin{array}{l}\text { probably } \\
\text { pathogenic }\end{array}$ & $\begin{array}{l}\text { unstable, } \\
\text { destabilising, } \\
\text { pathogenic }\end{array}$ \\
\hline
\end{tabular}




\section{Supporting Table S3:}

TSC2 variants (amino acids 900 - 1807). TSC2 nucleotide changes and exon numbers are given according to the TSC2 LOVD (http://www.lovd.nl/TSC2). Nucleotide numbering reflects the TSC2 cDNA numbering (Genbank X75621; GI:450351) with +1 corresponding to the A of the ATG translation initiation codon in the reference sequence, according to journal guidelines (www.hgvs.org/mutnomen). Amino acid changes are numbered according to the sequence of the wild-type TSC2 expression construct used [European Chromosome 16 Tuberous Sclerosis Consortium, 1993] (Genbank X75621; GI:450351). Amino acid changes according to the TSC2 LOVD are also given, where this differs from the original sequence due to the inclusion of 23 amino acids encoded by the alternatively spliced exon 31 (Genbank X75621.1; GI:4071057). Nucleotide changes predicted to cause splicing defects are marked with an asterisk.

Amino acid substitutions predicted by SIFT to be tolerated (T) or not tolerated (NT) are indicated. Previously untested variants are indicated in bold. Links to the original references describing the different variants can be accessed via the TSC2 LOVD. Variants not previously listed in the TSC2 LOVD are indicated as 'not listed'.

\begin{tabular}{|c|c|c|c|c|}
\hline Exon & Variant & $\begin{array}{l}\text { SIFT } \\
\text { prediction }\end{array}$ & $\begin{array}{l}\text { LOVD } \\
\text { classification }\end{array}$ & $\begin{array}{l}\text { Functional } \\
\text { assessment }\end{array}$ \\
\hline 23 & $\begin{array}{l}\text { c. } 2713 \mathrm{C}>\mathrm{G} \\
\text { (p.R905G) }\end{array}$ & NT & $\begin{array}{l}\text { probably } \\
\text { pathogenic }\end{array}$ & pathogenic \\
\hline 23 & $\begin{array}{l}\text { c. } 2714 G>A \\
\text { (p.R905Q) }\end{array}$ & NT & pathogenic & pathogenic \\
\hline 23 & c. $2713 \mathrm{C}>\mathrm{T}$ & NT & pathogenic & pathogenic \\
\hline
\end{tabular}




\begin{tabular}{|c|c|c|c|c|}
\hline & (p.R905W) & & & \\
\hline 24 & c.2765T $>$ G (p.L916R) & NT & $\begin{array}{l}\text { probably } \\
\text { pathogenic }\end{array}$ & $\begin{array}{l}\text { unstable, } \\
\text { pathogenic }\end{array}$ \\
\hline 25 & $\begin{array}{l}\text { c.2853A }>\text { T } \\
(\text { p.R951S) }\end{array}$ & $\mathbf{T}$ & $\begin{array}{l}\text { probably } \\
\text { pathogenic; } \\
\text { updated to } \\
\text { unkown }\end{array}$ & probably neutral \\
\hline 25 & $\begin{array}{l}\text { c.2963G >C } \\
\text { (p.R988P) }\end{array}$ & $\mathbf{T}$ & not listed & probably neutral \\
\hline 26 & $\begin{array}{l}\text { c. } 2978 \mathrm{C}>\mathrm{T} \\
\text { (p.T993M) }\end{array}$ & $\mathrm{T}$ & $\begin{array}{l}\text { probably no } \\
\text { pathogenicity }\end{array}$ & probably neutral \\
\hline 26 & $\begin{array}{l}\text { c.3082G }>A \\
(p . D 1028 N)\end{array}$ & NT & not listed & $\begin{array}{l}\text { unstable, } \\
\text { pathogenic }\end{array}$ \\
\hline 26 & $\begin{array}{l}\text { c.3095G }>C \\
(p . R 1032 P)\end{array}$ & NT & $\begin{array}{l}\text { probably } \\
\text { pathogenic }\end{array}$ & pathogenic \\
\hline 26 & $\begin{array}{l}\text { c.3106T >C } \\
\text { (p.S1036P) }\end{array}$ & NT & \begin{tabular}{|l|} 
probably \\
pathogenic
\end{tabular} & pathogenic \\
\hline 27 & $\begin{array}{l}\text { c.3182T>C } \\
\text { (p.L1061P) }\end{array}$ & NT & not listed & $\begin{array}{l}\text { unstable, } \\
\text { pathogenic }\end{array}$ \\
\hline 27 & $\begin{array}{l}\text { c.3203C>A } \\
\text { (p.T1068I) }\end{array}$ & NT & unknown & pathogenic \\
\hline 27 & $\begin{array}{l}\text { c. } 3224 \mathrm{C}>\mathrm{T} \\
\text { (p.T1075I) }\end{array}$ & NT & unknown & probably neutral \\
\hline 28 & $\begin{array}{l}\text { c.3382C }>T \\
(p . R 1122 C)\end{array}$ & $\mathbf{T}$ & not listed & probably neutral \\
\hline
\end{tabular}




\begin{tabular}{|c|c|c|c|c|}
\hline 29 & $\begin{array}{l}\text { c.3476G > T } \\
(p . R 1159 L)\end{array}$ & $\mathbf{T}$ & unknown & $\begin{array}{l}\text { unstable, } \\
\text { probably neutral }\end{array}$ \\
\hline 29 & $\begin{array}{l}\text { c.3476G }>A \\
(p . R 1159 Q)\end{array}$ & $\mathbf{T}$ & $\begin{array}{l}\text { no known } \\
\text { pathogenicity }\end{array}$ & $\begin{array}{l}\text { unstable, } \\
\text { probably neutral }\end{array}$ \\
\hline 29 & $\begin{array}{l}\text { c.3475C }>\text { T } \\
\text { (p.R1159W) }\end{array}$ & $\mathbf{T}$ & unknown & probably neutral \\
\hline 29 & $\begin{array}{l}\text { c.3596T }>G \\
\text { (p.V1199G) }\end{array}$ & $\mathrm{T}$ & unknown & $\begin{array}{l}\text { unstable, } \\
\text { pathogenic }\end{array}$ \\
\hline 29 & $\begin{array}{l}\text { c.3598C }>T \\
(\text { p.R1200W) }\end{array}$ & NT & pathogenic & $\begin{array}{l}\text { unstable, } \\
\text { pathogenic }\end{array}$ \\
\hline 29 & $\begin{array}{l}\text { c.3605C }>A \\
(\text { p.P1202H) }\end{array}$ & $\mathbf{T}$ & not listed & pathogenic \\
\hline 30 & $\begin{array}{l}\text { c.3611G }>A^{*} \\
\text { (p.G1204E) }\end{array}$ & NT & $\begin{array}{l}\text { probably } \\
\text { pathogenic }\end{array}$ & pathogenic \\
\hline 32 & $\begin{array}{l}\text { c.3943C>G } \\
\text { (p.P1315A/ } \\
\text { P1292A) }\end{array}$ & $\mathrm{T}$ & unknown & probably neutral \\
\hline 33 & $\begin{array}{l}\text { c.4105C>T } \\
(p . R 1369 W / \\
\text { R1346W) }\end{array}$ & $\mathbf{T}$ & $\begin{array}{l}\text { probably no } \\
\text { pathogenicity }\end{array}$ & probably neutral \\
\hline 33 & $\begin{array}{l}\text { c.4225C>T } \\
\text { (p.R1409W/ } \\
\text { R1386W) }\end{array}$ & $\mathbf{T}$ & $\begin{array}{l}\text { no known } \\
\text { pathogenicity }\end{array}$ & probably neutral \\
\hline 33 & $\begin{array}{l}\text { c. } 4298 \mathrm{C}>\mathrm{T} \\
\text { (p.S1433L/S1410L) }\end{array}$ & $\mathrm{T}$ & unknown & probably neutral \\
\hline
\end{tabular}




\begin{tabular}{|c|c|c|c|c|}
\hline 33 & $\begin{array}{l}\text { c.4316G>A } \\
\text { (p.G1439D/G1416D) }\end{array}$ & $\mathrm{T}$ & unknown & probably neutral \\
\hline 33 & $\begin{array}{l}\text { c.4490C>G } \\
\text { (p.P1497R/P1474R) }\end{array}$ & $\mathbf{N T}$ & pathogenic & pathogenic \\
\hline 33 & $\begin{array}{l}\text { c.4489C }>T \\
(\text { p.P1497S/P1474S) }\end{array}$ & $\mathbf{T}$ & not listed & pathogenic \\
\hline 33 & $\begin{array}{l}\text { c.4489C>A } \\
(p . P 1497 T / P 1474 T)\end{array}$ & NT & $\begin{array}{l}\text { probably } \\
\text { pathogenic }\end{array}$ & pathogenic \\
\hline 34 & $\begin{array}{l}\text { c.4499T >G } \\
(\text { p.V1500G/V1477G) }\end{array}$ & $\mathbf{T}$ & $\begin{array}{l}\text { probably } \\
\text { pathogenic }\end{array}$ & pathogenic \\
\hline 34 & $\begin{array}{l}\text { c.4525_4527del } \\
\text { (p.1510delF/ } \\
\text { 1487delF) }\end{array}$ & - & $\begin{array}{l}\text { no known } \\
\text { pathogenicity }\end{array}$ & probably neutral \\
\hline 35 & $\begin{array}{l}\text { c.4601T }>A \\
\text { p.L1534H/L1511H) }\end{array}$ & NT & $\begin{array}{l}\text { probably } \\
\text { pathogenic }\end{array}$ & $\begin{array}{l}\text { unstable, } \\
\text { pathogenic }\end{array}$ \\
\hline 35 & $\begin{array}{l}\text { c. } 4604 \mathrm{~A}>\mathrm{C} \\
\text { (p.D1535A/D1512A) }\end{array}$ & NT & unknown & pathogenic \\
\hline 35 & $\begin{array}{l}\text { c.4643T }>C \\
(p . L 1548 P / L 1525 P)\end{array}$ & NT & unknown & $\begin{array}{l}\text { unstable, } \\
\text { destabilising, } \\
\text { pathogenic }\end{array}$ \\
\hline 36 & $\begin{array}{l}\text { c. } 4700 \mathrm{G}>\mathrm{T} \\
(\mathrm{p} . \mathrm{G} 1567 \mathrm{~V} \\
/ \mathrm{G} 1544 \mathrm{~V})\end{array}$ & NT & unknown & $\begin{array}{l}\text { destabilising, } \\
\text { pathogenic }\end{array}$ \\
\hline 36 & $\begin{array}{l}\text { c.4726_4783del } \\
\text { (p.1575del19/ }\end{array}$ & - & unknown & $\begin{array}{l}\text { unstable, } \\
\text { pathogenic }\end{array}$ \\
\hline
\end{tabular}




\begin{tabular}{|c|c|c|c|c|}
\hline & 1552del19) & & & \\
\hline 36 & $\begin{array}{l}\text { c.4733T }>C \\
\text { (p.L1578P/L1555P) }\end{array}$ & NT & $\begin{array}{l}\text { probably } \\
\text { pathogenic }\end{array}$ & $\begin{array}{l}\text { unstable, } \\
\text { destabilising, } \\
\text { pathogenic }\end{array}$ \\
\hline 36 & $\begin{array}{l}\text { c. } 4735 \mathrm{G}>\mathrm{A} \\
\text { (p.G1579S/G1556S) }\end{array}$ & NT & $\begin{array}{l}\text { probably } \\
\text { pathogenic }\end{array}$ & pathogenic \\
\hline 37 & $\begin{array}{l}\text { c.4918C>T } \\
(\mathrm{p} . \mathrm{H} 1640 \mathrm{Y} / \mathrm{H} 1617 \mathrm{Y})\end{array}$ & NT & unknown & pathogenic \\
\hline 37 & $\begin{array}{l}\text { c.4925G }>A \\
\text { (p.G1642D/G1619D) }\end{array}$ & NT & unknown & pathogenic \\
\hline 37 & $\begin{array}{l}\text { c.4927A }>C \\
(p . N 1643 H / N 1620 H)\end{array}$ & NT & unknown & pathogenic \\
\hline 37 & $\begin{array}{l}\text { c.4928A }>T \\
(p . N 1643 I / N 1620 I)\end{array}$ & NT & $\begin{array}{l}\text { probably } \\
\text { pathogenic }\end{array}$ & pathogenic \\
\hline 37 & $\begin{array}{l}\text { c.4929C>G } \\
(p . N 1643 K / N 1620 K)\end{array}$ & NT & $\begin{array}{l}\text { probably } \\
\text { pathogenic }\end{array}$ & $\begin{array}{l}\text { unstable, } \\
\text { pathogenic }\end{array}$ \\
\hline 37 & $\begin{array}{l}\text { c.4928A }>\text { G } \\
(p . N 1643 S / N 1620 S)\end{array}$ & NT & not listed & pathogenic \\
\hline 37 & $\begin{array}{l}\text { c.4937T }>\mathrm{G} \\
(\mathrm{p} . \mathrm{V} 1646 \mathrm{G} / \mathrm{V} 1623 \mathrm{G})\end{array}$ & NT & unknown & $\begin{array}{l}\text { unstable, } \\
\text { destabilising, } \\
\text { pathogenic }\end{array}$ \\
\hline 38 & $\begin{array}{l}c .5057 \mathrm{~A}>\mathrm{C} \\
(\mathrm{p.Q1686P/Q1663P})\end{array}$ & $\mathbf{T}$ & not listed & $\begin{array}{l}\text { unstable, } \\
\text { destabilising, } \\
\text { pathogenic }\end{array}$ \\
\hline 39 & c.5138G $>A$ & NT & unknown & unstable, \\
\hline
\end{tabular}




\begin{tabular}{|c|c|c|c|c|}
\hline & (p.R1713H/R1690H) & & & $\begin{array}{l}\text { destabilising, } \\
\text { pathogenic }\end{array}$ \\
\hline 40 & $\begin{array}{l}\text { c.5228G }>A \\
\text { (p.R1743Q/R1720Q) }\end{array}$ & NT & pathogenic & pathogenic \\
\hline 40 & $\begin{array}{l}\text { c.5227C>T } \\
(\mathrm{p} . \mathrm{R} 1743 \mathrm{~W} / \\
\mathrm{R} 1720 \mathrm{~W})\end{array}$ & NT & pathogenic & pathogenic \\
\hline 40 & $\begin{array}{l}\text { c.5238_5255del } \\
\text { (p.1746del6/ } \\
\text { 1723del6) }\end{array}$ & - & pathogenic & $\begin{array}{l}\text { unstable, } \\
\text { destabilising, } \\
\text { pathogenic }\end{array}$ \\
\hline 41 & $\begin{array}{l}\text { c.5383C }>\mathrm{T} \\
(\mathrm{p} . \mathrm{R} 1795 \mathrm{C} / \mathrm{R} 1772 \mathrm{C})\end{array}$ & NT & $\begin{array}{l}\text { no known } \\
\text { pathogenicity }\end{array}$ & probably neutral \\
\hline 41 & $\begin{array}{l}\text { c.5386C }>\mathrm{A} \\
(\text { p.L1796I/L1773I) }\end{array}$ & $\mathbf{T}$ & $\begin{array}{l}\text { probably } \\
\text { pathogenic; } \\
\text { updated to } \\
\text { unknown }\end{array}$ & probably neutral \\
\hline
\end{tabular}

